\title{
Descrições morfológicas de palinomorfos holocênicos de um fragmento da Savana Estépica Parque em Barra do Quaraí, Rio Grande do Sul, Brasil
}

\author{
Andréia Cardoso Pacheco EVALDT ${ }^{1,2}$, Soraia Girardi BAUERMANN ${ }^{1}$ \& Paulo A. SOUZA ${ }^{2}$
}

1. Laboratório de Palinologia, Universidade Luterana do Brasil. Av. Farroupilha, 8.001, CEP 92.425-900, Canoas, RS, Brasil. E-mail: andreia.pacheco@ulbra.br, soraia.bauermann@ulbra.br.

2. Laboratório de Palinologia Marleni Marques Toigo, Instituto de Geociências, Universidade Federal do Rio Grande do Sul. Av. Bento Gonçalves, 9.500, CEP 91.501-970, Porto Alegre, RS, Brasil. E-mail: paulo.alves.souza@ufrgs.br.

Recebido em 02/2013. Aceito para publicação em 11/2013.

Versão online publicada em 02/12/2013 (www.pesquisasemgeociencias.ufrgs.br)

\begin{abstract}
Resumo - Apesar de sua área relativamente pequena no extremo oeste do Rio Grande do Sul, a Savana Estépica Parque constitui uma unidade singular na fitogeografia do Estado, com carência de investigação sobre sua his-

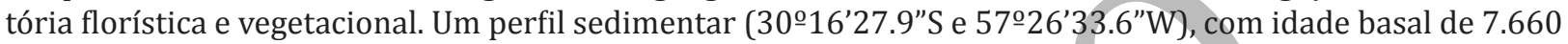
${ }^{14} \mathrm{C}$ anos AP, foi realizado, com extração de 86 amostras, além de 15 amostras superficiais coletadas, provenientes desta formação vegetacional, no município de Barra do Quaraí, para análises palinológicas. Neste trabalho, são apresentadas descrições e ilustrações de 97 palinomorfos (10 fungos, quatro algas, dois briófitos, seis pteridófitos, uma gimnosperma, 73 angiospermas e um zooclasto) registrados na área de estudo, incluindo gêneros e espécies que caracterizam a vegetação Savana Estépica Parque, tais como Aspidosperma quebracho-blanco Schltdl., Parkinsonia aculeata L., Prosopis L., Tillandsia L. e Vachellia caven (Molina) Seigler \& Ebinger, além da macrófita aquática Lemna L., cuja descrição é inédita para América Latina.
\end{abstract}

Palavras-chave: Pólen, Parque do Espinilho, Bioma Pampa, Holoceno, Sul do Brasil.

\begin{abstract}
MORPHOLOGICAL DESCRIPTIONS OF HOLOCENE PALYNOMORPHS FROM A FRAGMENT OF THE "SAVANA ESTÉPICA PARque" IN BARRA do QuARAí, Rio GRANDE do Sul, Brazil. Despite its relatively small area in westernmost portion of Rio Grande do Sul, the "Savana Estepica Parque" constitutes a single unit in the phytogeography of the State, lacking research on its floristic and vegetation histories. A total of 86 samples from a sedimentary profile $\left(30^{\circ} 16^{\prime} 27.9^{\prime \prime} \mathrm{S}\right.$ and $\left.57^{\circ} 26^{\prime} 33.6^{\prime \prime} \mathrm{W}\right)$ with a basal age of $7,660^{14} \mathrm{C}$ years BP, and 15 surface samples were collected from this vegetational formation, in Barra do Quaraí Municipality, for palynological analysis. In this paper, descriptions and illustrations of 97 palynomorphs are presented (10 fungi, four algae, two bryophytes, six ferns, one gymnosperm, 73 angiosperms and one zooclast) including genus and species that characterizes the "Savana Estépica Parque" vegetation, such as Aspidosperma quebracho-blanco Schltdl., Parkinsonia aculeata L., Prosopis L., Tillandsia L. and Vachellia caven (Molina) Seigler \& Ebinger, besides the macrophyte Lemna L., which description is unknown for the Latin America.
\end{abstract}

Keywords: Pollen, “Parque do Espinilho”, "Bioma Pampa”, Holocene, Southern Brazil.

\section{Introdução}

O conhecimento da palinologia do Quaternário da região da Campanha, oeste do Rio Grande do Sul (RS), quando comparado com as demais regiões fitofisiográficas do Estado, mostra-se incipiente, uma vez que a maioria dos estudos sobre palinologia do Quaternário do Estado foi desenvolvida na Planície Costeira, com algumas contribuições pontuais na região do Planalto (Bauermann et al., 2009). A maior parte dos trabalhos de palinologia do Quaternário desenvolvidos no Brasil é advinda de perfurações em turfeiras, que documentam de forma significativa a sucessão vegetacional, bem como suas implicações paleoclimáticas. Para a Campanha Gaúcha não existem trabalhos completos disponíveis, com apenas um estudo publicado na ínte- gra na região de ecótono entre os biomas Mata Atlântica e Pampa (Behling et al., 2005). Além disso, não há registros da ocorrência de turfeiras não antropizadas nas áreas cobertas pela Savana Estépica Parque, que comportam, de maneira geral, depósitos quaternários de origem aluvial e fluvial (Da-Rosa, 2009).

Com o objetivo de entender as modificações paleoclimáticas e paleoambientais ocorridas no Holoceno e suas consequências na fitofisionomia de um fragmento de savana estépica localizado do extremo oeste do Estado, foram realizadas análises polínicas em uma seção sedimentar (composta por depósitos fluviais) e em amostras de superfície. Este trabalho constitui parte de um projeto de maior âmbito, que visa à reconstituição paleoambiental e paleovegetacional deste ecossistema no Estado, incluindo implicações paleoclimáticas. 


\section{2 Área de estudo}

\subsection{Caracterização da área de estudo}

A formação vegetacional Savana Estépica Parque (IBGE, 1992) encontra-se restrita à área da Unidade de Conservação Parque Estadual do Espinilho (PESP). Situado na porção sudoeste da região do Planalto da Campanha (Galvani \& Baptista, 2003), o PESP localiza-se em Barra do Quaraí (Fig. 1), município mais ocidental do Estado e mais distante da capital, Porto Alegre (717 $\mathrm{km}$ ). Constitui uma unidade peculiar sob os pontos de vista florístico e vegetacional, o que justifica a sua segregação em uma província fitogeográfica distinta: a
Província do Espinhal, vinculada às planícies sedimentares, em uma estreita faixa adjacente ao Rio Uruguai, entre os rios Quaraí e Ibicuí (Alves \& Marchiori, 2011). Esta formação vegetacional está registrada em outros países da América do Sul: Argentina e Uruguai. No Brasil, ocorre somente no RS (Watzlawick et al., 2010). A Savana Estépica Parque é caracterizada pela associação de Aspidosperma quebracho-blanco, Parkinsonia aculeata, Prosopis, Tillandsia e Vachellia caven. Dentro da área do PESP ocorre também Mata Ciliar, nas margens dos rios Quaraí e Uruguai. Na região predomina o clima fundamental Cfa2 de Köppen, com temperatura média anual em torno de $20^{\circ} \mathrm{C}$, média máxima chegando a 34 ${ }^{\circ} \mathrm{C}$, em janeiro, e média mínima registrando $8^{\circ} \mathrm{C}$, em julho (Rio Grande do Sul, 2012).

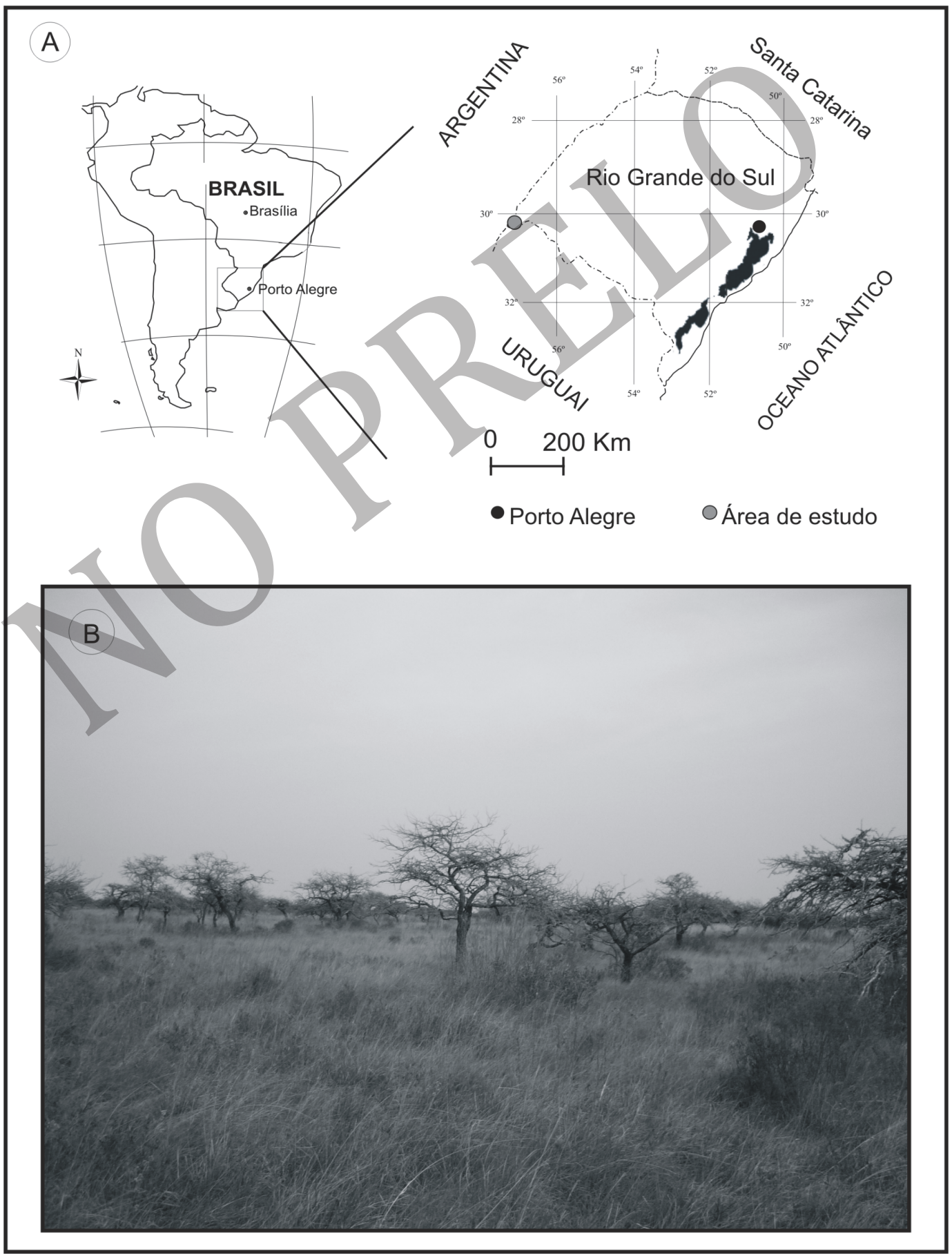

Figura 1. Área de estudo: (A) Mapa de localização da área de estudo; (B) aspecto geral da vegetação atual da formação vegetacional Savana Estépica Parque. 


\subsection{Materiais e métodos}

A cobertura holocênica da qual foram coletadas as amostras está assentada sobre duas unidades estratigráficas quaternárias distintas, a Aloformação Guterres e a Formação Touro Passo. No solo que recobre a Aloformação Guterres foram coletadas 15 amostras superficiais, em diferentes ambientes do PESP, enquanto um perfil sedimentar $\left(30^{\circ} 16^{\prime} 27.9^{\prime \prime}\right.$; $\left.5^{\circ} 26^{\prime} 33.6^{\prime \prime} \mathrm{W}\right) \mathrm{com}$ $455 \mathrm{~cm}$ de profundidade foi obtido, pelo método de coleta em trincheiras (Salgado-Labouriau, 2007), na porção da cobertura holocênica que recobre a Formação Touro Passo. A partir deste perfil, 86 amostras foram extraídas para análise palinológica (em intervalos de 5 cm cada). Para o tratamento químico das amostras, foi utilizada a metodologia proposta por Faegri \& Iversen (1989), pela qual as amostras são tratadas com $\mathrm{HCl}, \mathrm{HF}$, KOH e acetólise, com retenção da fração menor que 250 $\mu \mathrm{m}$ por peneiramento. As lâminas foram montadas em gelatina glicerinada e encontram-se depositadas nos laboratórios de Palinologia da Universidade Luterana do Brasil (ULBRA) e Laboratório de Palinologia Marleni Marques Toigo da Universidade Federal do Rio Grande do Sul (UFRGS).

A identificação dos palinomorfos foi realizada sob microscopia óptica em aumento de 400x utilizando-se microscópio Leica DMLB, com base na coleção de referência (palinoteca) do Laboratório de Palinologia da ULBRA e consulta à bibliografia especializada: Heusser (1971), Markgraf \& D’ Antoni (1978), van Geel (1978), Hooghiemstra (1984), Roubik \& Moreno (1991), Behling (1993), Lorscheitter et al. (1998, 1999, 2001, 2002, 2005), Colinvaux et al. (1999), Kapp et al. (2000), Melhem et al. (2003), Neves \& Bauermann (2004), Pire et al. (2006), Leonhardt \& Lorscheitter (2007), Cancelli et al. $(2007,2010,2012 \mathrm{a}, 2012 \mathrm{~b})$, Roth \& Lorscheitter (2008), Scherer \& Lorscheitter (2008), Evaldt et al. (2009, 2011), Macedo et al. (2009), Bauermann et al. (2010) e Radaeski et al. (2011). A descrição segue metodologia proposta por Barth \& Melhem (1988). Sempre que possível, foram realizadas medidas dos diâmetros polar e equatorial em 25 espécimes. A terminologia segue proposição de Barth \& Melhem (1988) e Punt et al. (2007). Os autores das espécies foram consultados em banco de dados especializado: The International Plant Name Index (2005) e Lista de Espécies da Flora do Brasil (2012).

Os palinomorfos são apresentados em ordem evolutiva, utilizando-se Hibbett et al. (2007) para fungos, Guiry \& Guiry (2012) para algas, Tryon \& Tryon (1982) para pteridófitos, van Geel (1978) para os táxons de animais e APG III (2009) para angiospermas. As fotomicrografias foram realizadas em microscópio óptico sob aumento de 1000x, com máquina digital acoplada. As ilustrações foram concebidas utilizando-se os softwares Corel DRAW e Corel PHOTO-PAINT, versões 12.0.

\section{Resultados}

São apresentadas descrições e ilustrações de 97 palinomorfos provenientes do perfil sedimentar e das amostras de superfície. A datação radiocarbônica ${ }^{14} \mathrm{C}$ da base do perfil sedimentar apontou a idade de 7.660 anos AP, posicionando o intervalo amostrado no Holoceno médio. Entretanto, os níveis palinologicamente férteis são oriundos do intervalo correspondente ao Holoceno tardio, cuja amostra mais antiga datou 3.380 anos AP. Todos os táxons estão ilustrados nas figuras $2 \mathrm{a}$ 109. Informações sobre as respectivas numerações das lâminas e coordenadas 'England Finder' dos espécimes ilustrados são fornecidos no apêndice 1. A distribuição estratigráfica dos táxons no perfil e suas ocorrências nas amostras superficiais estão disponíveis na segunda parte desta contribuição (Evaldt et al., submetido). Dados ecológicos de cada espécie, quando disponíveis, seguem após a respectiva descrição.

\section{Fungi}

Filo Glomeromycota

Classe Glomeromycetes

Ordem Glomerales

Família Glomeraceae

Glomus Tus. \& C. Tus.

(Figs. 2-3)

Descrição: clamidósporo elipsoidal, de superfície psilada e coloração variando de amarelo claro a escuro, preso a um filamento de hifa cenocítica formando um micélio ramificado.

Dimensões (25 espécimes): diâmetro das vesículas entre 45 e $58 \mu \mathrm{m}$.

Observações: citado anteriormente como Rhizophagites Rosendahl (Lorscheitter, 1988) e Rhizophagus Dang (Neves \& Lorscheitter, 1992; Neves \& Bauermann, 2003).

Dados ecológicos: são fungos micorrízicos arbusculares que vivem principalmente associados às raízes das fanerógamas (Trufem, 1999).

\section{Filo Ascomycota}

Classe Dothideomycetes

Ordem Pleosporales

Família Tetraplosphaeriaceae

Tetraplosphaeria tetraploa (Scheuer) Kaz. Tanaka \& Hirayma

(Fig. 4)

Descrição: conídio verrucoso, de coloração castanho escuro, provido de quatro apêndices septados, psilado de tamanho variável.

Dimensões (25 espécimes): diâmetro maior do conídio entre 36 e $55 \mu \mathrm{m}$ e diâmetro menor entre 20 e $30 \mu \mathrm{m}$. Observações: citado anteriormente como Tetraploa aristata Berk. \& Br. (Neves, 1998; Bauermann, 2003, Macedo et al., 2009).

Dados ecológicos: ocorre comumente sobre as folhas da serrapilheira (van Gell, 1978). 
Classe Leotiomycetes

Ordem Helotiales

Família Helotiaceae

Bryophytomyces sphagni (Navashin) Cif.

(Fig. 5)

Descrição: esporo esférico, tênue, com estrias anastomosadas que formam estruturas poligonais; distância entre as placas de 4 a $6 \mu \mathrm{m}$.

Dimensões (10 espécimes): diâmetro entre 20 e $33 \mu \mathrm{m}$. Observações: citado anteriormente como Tilletia sphagnii Navashin, ou tipo 27 de van Geel (1978).

Dados ecológicos: espécie parasita do gênero Sphagnum (Dill.) Hedw (van Geel, 1978).

Classe Sordariomycetes

Ordem Sordariales

Família Chaetomiaceae

Ascósporo tipo Chaetomium Kunze

(Fig. 6)

Descrição: ascósporo de cor castanha, elipsoidal com ápices cônicos em cada uma de suas extremidades; porado em uma das extremidades, com a parede adelgaçando na extremidade oposta ao poro.

Dimensões (25 espécimes): diâmetro entre 10 e 15 m.

Família Sordariaceae

\section{Gelasinospora adjuncta Cain}

(Fig. 7)

Descrição: ascósporo elipsoidal, asseptado, de coloração castanho escura e exina psilada; pequenas perfurações medindo aproximadamente $3 \mu \mathrm{m}$, regularmente distribuídas.

Dimensão (1 espécime): diâmetro maior $26 \mu \mathrm{m}$, diâmetro menor $19 \mu \mathrm{m}$.

Dados ecológicos: espécie decompositora de madeiras carbonizadas, lignina e excremento de animais (van Geel, 1978).

Ordem Trichosphaeriales

Família Trichosphaeriaceae

Khuskia H.J.Huds

(Fig. 8)

Descrição: conídios elípticos, de coloração castanho escura, apresentando superfície espessa, psilada e com uma fenda longitudinal.

Dimensões (25 espécimes): diâmetro maior entre 20 e $32 \mu \mathrm{m}$.

Observações: citado anteriormente como Nigrospora Zimm. (Macedo et al., 2009; Cancelli et al., 2012a).

Dados ecológicos: ocorrem amplamente em solos de florestas, pastagens, manguezais, solos arenosos (Domsch et al., 1980).

Ordem Magnporthales

Família Magnaporthaceae

Gaeumannomyces cf. caricis J. Walker

(Fig. 9)

Descrição: esporângios discoides, de coloração casta- nho escura e margens lobadas; superfície psilada, muito fina, apresentando poro central.

Dimensões (25 espécimes): diâmetro do esporângio entre 13 e $27 \mu \mathrm{m}$.

Observações: citado anteriormente como "cf. Enthophlyctis lobata" por van Geel (1978).

Dados ecológicos: são fungos parasitas ou saprófitas de caules de raízes de Poaceae (von Arx, 1974).

\section{Esporos indeterminados}

(Figs. 10-18)

Descrição: esporo de fungo unicelular, bicelular ou multicelular, formato elipsoidal ou esférico, coloração amarelo claro à marrom escura, hialina, apresentando superfície psilada, levemente escabrada, verrucada, estriada ou reticulada; mono ou diaperturado com abertura em forma circular, alongada ou hemiconvexa.

Dimensões (36 espécimes): diâmetro maior entre 19 e $118 \mu \mathrm{m}$ e diâmetro menor entre 6 e $32 \mu \mathrm{m}$.

Dados ecológicos: segundo van Geel (1978) a maioria das estruturas de fungos encontradas nos sedimentos podem ser consideradas autóctones.

\section{Frutifícação de fungo}

(Fig. 19)

Descrição: corpo frutífero de fungo marrom escuro no centro, tornando-se hialino na periferia; ostíolo medindo cerca de $8 \mu \mathrm{m}$ e células próximas ao ostíolo medindo entre 2 e $3 \mu \mathrm{m}$; nas bordas é possível ver a localização das primeiras hifas.

Dimensões (3 espécimes): diâmetro maior entre 70 e $93 \mu \mathrm{m}$ e o diâmetro menor entre 50 e $60 \mu \mathrm{m}$.

Dados ecológicos: segundo van Geel (1978), este exemplar pode ser considerado em um estágio intermediário, pois já formou o ostíolo, mas ainda não apresenta hifas desenvolvidas nas bordas do corpo frutífero.

\section{Hifas de fungo}

(Fig. 20)

Descrição: filamento celular simples ou ramificado, septado/hemisseptado ou cenocítico, de coloração castanho claro a escuro, fragmentado.

Dimensões: variável, o exemplar ilustrado mede $88 \mu \mathrm{m}$.
Algae
Divisão Chlorophyta
Classe Trebouxiophyceae
Ordem Trebouxiales
Família Botryococcaceae
Botryococcus Kützing
(Fig. 21)

Descrição: colônia irregularmente lobada, de coloração castanho claro, formada por indivíduos unicelulares concentricamente dispostos de superfície psilada.

Dimensões (6 colônias): diâmetro maior entre 78 e $92 \mu \mathrm{m}$.

Dados ecológicos: alga relacionada a ambientes de água doce, encontrados em corpos d'água de tamanhos 
variados (Torgan et al., 2001; Medeanic, 2006)

Divisão Charophyta

Classe Zygnematophyceae

Ordem Zygnematales

Família Zygnemataceae

\section{Debarya Wittrock}

(Fig. 22)

Descrição: zigósporo formado por dois hemisférios hialinos com um espessamento anelar característico em cada um deles, em vista frontal; região equatorial com estrias finas dispostas longitudinalmente.

Dimensões (2 espécimes): diâmetro maior 35 e $47 \mu \mathrm{m}$. Observações: os zigospórios encontrados apresentam apenas um dos hemisférios, fato também observado por Scherer \& Lorscheitter (2008) e Macedo et al. (2009) para outras localidades no RS.

Dados ecológicos: a ocorrência dos zigósporos está relacionada a ambientes dulciaquícolas, mesotróficos, rasos e estagnados (van Geel \& van der Hammen, 1978).

\section{Spirogyra Link}

(Fig. 23)

Descrição: zigósporo elipsoidal, psilado hialino de coloração amarelo claro, com parede celular lisa e fenda característica acompanhando o maior eixo do zigósporo.

Dimensões (25 espécimes): diâmetro equatorial maior entre 37 e $41 \mu \mathrm{m}$, diâmetro menor entre 20 e 24 $\mu \mathrm{m}$.

Dados ecológicos: segundo van Geel \& van der Hammen (1978) este tipo de zigósporo representa um grupo de espécies que não pode ser distinguida, através da identificação do zigósporo, em nível genérico.

\section{Pseudoschizaea rubina Rossignol ex Christopher}

(Fig. 24)

Descrição: zigósporo hialino, circular em vista frontal, inaperturado, apresentado estrias finas e concêntricas formando anéis ou espiras sobre cada hemi-célula.

Dimensões (25 espécimes): diâmetro em vista frontal entre 33 e $42 \mu \mathrm{m}$.

Dados ecológicos: ocorre em ambientes dulciaqüícolas ou sobre solos úmidos (Rossignol, 1962; Rich \& Pirkle, 1994).

\section{Bryophyta}

Classe Bryopsida

Ordem Bryales

Família Bartramiaceae

Bartramia Hedw.

\section{(Fig. 25)}

Descrição: esporo esferoidal, heteropolar, radiossimétrico, circular a subtriangular em vista frontal, convexos em vista polar; exospório microequinado a psilado no polo distal; espinhos finos, escassos a abundantes, irregularmente a regularmente distribuídos; no polo proximal ocorrem alguns espinhos.
Dimensões (1 espécime): diâmetro equatorial $33 \mu \mathrm{m}$. Dados ecológicos: briófita nativa do Brasil, com ocorrência registrada para o Bioma Pampa (Lista de Espécies da Flora do Brasil, 2012).

Divisão Anthocerotophyta

Classe Anthoceratopsida

Ordem Anthocerotales

Família Anthocerataceae

Phaeoceros laevis (L.) Prosk.

(Fig. 26)

Descrição: esporo trilete (raios com extremidade distal bifurcada), heteropolar, radiossimétrico, circular a subtriangular em vista frontal, convexos em vista polar; exospório microequinado a psilado no polo distal; espinhos finos, escassos a abundantes, irregularmente a regularmente distribuídos; no polo proximal podem ser visualizados poucos espinhos.

Dimensões (25 espécimes): diâmetro equatorial entre 43 e $50 \mu \mathrm{m}$.

Dados ecológicos: ocorre em solos úmidos (Hässel de Menéndez, 1962, 1987).

\section{Pteridophyta}

Classe Filicopsida

Ordem Polypodiales

Família Polypodiaceae

tipo Microgramma vacciniifolia (Langst \& Fisch.) Copel.

(Fig. 27)

Descrição: esporo monolete, grande, bilateralmente simétrico, elíptico em vista polar; exospório verrucado com verrugas irregularmente distribuídas na superfície do esporo; espinhos finos, escassos a abundantes, irregularmente a regularmente distribuídos.

Dimensões (6 espécimes): diâmetro equatorial entre 43 e $52 \mu \mathrm{m}$.

Dados ecológicos: a espécie Microgramma vacciniifolia ocorre em ambientes sombreados e abertos, com ampla distribuição no RS (Lorscheitter et al., 2005).

Família Cyatheaceae

Cyatheaceae

(Fig. 28)

Descrição: esporo trilete, médio a grande, heteropolar, oblato, convexo na face distal, âmbito triangular, exospório psilado com pequenos elementos disformes distribuídos irregularmente.

Dimensões (2 espécimes): diâmetro polar 29 e 36 $\mu \mathrm{m}$, diâmetro equatorial 49 e $55 \mu \mathrm{m}$.

Dados ecológicos: ocorrem comumente em florestas tropicais, úmidas e nebulares (Lorscheitter et al., 1999).

\section{Família Blechnaceae}

tipo Blechnum L.

(Fig. 29)

Descrição: esporo monolete, grande, bilateralmente 
simétrico, de coloração amarelo claro a escuro; exospório psilado; esporoderme medindo em média $2,7 \mu \mathrm{m}$.

Dimensões (23 espécimes): diâmetro polar entre 28 e $33 \mu \mathrm{m}$ e diâmetro equatorial entre 49 e $55 \mu \mathrm{m}$.

Dados ecológicos: plantas terrestres ou rupestres, raramente epífitas, com distribuição na América tropical. Ocorrem em pântanos, interior de matas palustres, bordas de florestas e áreas antropizadas (Tryon \& Tryon, 1982). No PESP é registrada a ocorrência de Blechnum sp. (Galvani \& Baptista, 2003).

\section{Adianthaceae}

(Fig. 30)

Descrição: esporo trilete médio, convexo na face distal, suboblato, âmbito subtriangular, marca trilete com margo, exósporio psilado medindo $2 \mu \mathrm{m}$ e perispório com pequenas projeções distribuídas irregularmente.

Dimensões (2 espécimes): diâmetro polar 26 e 30 $\mu \mathrm{m}$, diâmetro equatorial 36 e $40 \mu \mathrm{m}$.

Dados ecológicos: pteridófita nativa, de hábito herbáceo, de ocorrência associada às formações florestais (Lista de Espécies da Flora do Brasil, 2012).

\section{Esporo trilete indeterminado 1}

(Fig. 31)

Descrição:esporo trilete, âmbito subcircular, marca trilete de difícil visualização, exospório finamente escabrado e perispório ausente.

Dimensões (25 espécimes): diâmetro equatorial entre 57 e $68 \mu \mathrm{m}$.

\section{Esporo trilete indeterminado 2}

(Fig. 32)

Descrição: esporo trilete, âmbito subtriangular, marca trilete de difícil visualização; verrugas regularmente distribuídas ao longo de todo o esporo.

Dimensões (5 espécimes): diâmetro equatorial entre 100 e $130 \mu \mathrm{m}$.

\section{Gimnospermae}

Divisão Coniferophyta

Classe Coniferopsida

Ordem Coniferales

Família Pinaceae

Pinus L.

\section{(Fig. 33)}

Descrição: mônade, grão de pólen vesiculado, bissacado, de tamanho grande, heteropolares, de simetria bilateral, corpo central de forma elíptica com a presença de leptoma no polo distal; sacos aéreos reticulados, de fina espessura com retículos irregularmente distribuídos (padrão heterobrocado).

Dimensões (25 espécimes): diâmetro total (incluindo os sacos aéreos) entre 87 e $96 \mu \mathrm{m}$; corpo central medindo aproximadamente $53 \mu \mathrm{m}$.

Observações: espécie exótica cultivada no RS. Por ser adventícia no Estado é considerada uma espécie invasora (Lorenzi, 2003; Backes \& Irgang, 2004).
Dados ecológicos: árvore exótica introduzida no RS para cultivo, sendo considerada invasora nos ecossistemas naturais por se propagar autonomamente (Lorenzi, 2003).

\section{Angiospermae \\ Magnolídeas}

Ordem Laurales

Família Lauraceae

Nectandra Rottb.

(Fig. 34)

Descrição: mônade, grão de pólen médio, âmbito circular, esférico, inaperturado, exina microequinada; nexina com o dobro de espessura da sexina.

Dimensões (2 espécimes): diâmetro 27 e $33 \mu \mathrm{m}$.

Dados ecológicos: Lauraceae representa uma das famílias de maior destaque na composição florística dos ecossistemas florestais da Mata Atlântica e em florestas da Região Sul (Souza \& Lorenzi, 2008). Espécies do gênero Nectandra são árvores que geralmente crescem bem na vegetação secundária (Backes \& Irgang, 2002). Durante as saídas a campo foi coletada a espécie $\mathrm{Nec}$ tandra angustifolia (Scharader) Ness. (HERULBRA 4318), que pode chegar a até $12 \mathrm{~m}$ de altura e têm sua ocorrência registrada em toda Região Sul (Backes \& Nardino, 2003).

Ordem Piperales

Família Piperaceae

Peperomia Ruiz \& Pav.

(Fig. 35)

Descrição: mônade, grão de pólen pequeno, âmbito circular, subprolato, monocolpado ocasionalmente inaperturado, exina verrucada medindo $1 \mu \mathrm{m}$ de espessura.

Dimensões (25 espécimes): diâmetro equatorial entre 9 e $14 \mu \mathrm{m}$, diâmetro polar entre 9 e $12 \mu \mathrm{m}$.

Observações: existem dois gêneros ocorrentes na região sul do Brasil (Peperomia e Piper). Peperomia apresenta grãos de pólen com ornamentação verrucada, enquanto Piper têm ornamentação escabrada.

Dados ecológicos: a família Piperaceae é predominantemente tropical. 0 gênero Peperomia é composto por ervas terrestres ou epífitas não volúveis (Souza \& Lorenzi, 2008).

\section{Monocotiledôneas}

Ordem Alismatales

Família Araceae

\section{Lemna L.}

(Fig. 36)

Descrição: mônade, grão de pólen pequeno, âmbito circular, oblato esferoidal, monoporado, poro circular, exina microequinada medindo cerca de $1,5 \mu \mathrm{m}$ com espículos regularmente distribuídos em toda superfície do grão de pólen.

Dimensões (4 espécimes): diâmetro polar entre 21 e $23 \mu \mathrm{m}$ e diâmetro equatorial entre 24 e $25 \mu \mathrm{m}$. 
Dados ecológicos: são macrófitas aquáticas flutuantes livres que ocorrem na superfície da água. No Parque ocorrem Lemna gibba L. e Lemna valdiviana Phil (Galvani \& Baptista, 2003).

\section{Família Alismataceae}

Echinodorus grandiflorus (Cham. \& Schltdl.) Micheli

(Fig. 37)

Descrição: mônade, grão de pólen pequeno, âmbito circular, esférico, pantoporado (12 poros), exina tectada medindo $1 \mu \mathrm{m}$ de espessura; sobre o teto, observam-se pequenos espinhos $(1 \mu \mathrm{m})$ de bases largas contendo escabras entre eles; poros levemente deprimidos, circulares medindo $2,5 \mu \mathrm{m}$ de diâmetro recoberto por uma membrana granulada; nexina com o dobro da espessura da sexina.

Dimensões (13 espécimes): diâmetro entre 23 e 25 $\mu \mathrm{m}$.

Dados ecológicos: são macrófitas aquáticas que ocorrem enraizadas no substrato, com partes vegetativas inteiramente submersas ou emergentes, sendo também tolerantes à seca (Galvani \& Baptista, 2003).

\section{Sagittaria montevidensis Cham. \& Schltdl.}

(Fig. 38)

Descrição: mônade, grão de pólen médio, âmbito circular, esférico, pantoporado (12-14 poros), exina tectada medindo $1,2 \mu \mathrm{m}$ de espessura; sobre o teto, ocorrem pequenos espinhos $(1 \mu \mathrm{m})$ de bases largas contendo escabras entre eles; poros algumas vezes deprimidos, subcirculares medindo $5 \mu \mathrm{m}$ de diâmetro podendo estar recoberto por uma membrana granulada; sexina com o dobro da espessura da nexina.

Dimensões (17 espécimes): diâmetro entre 33 e 37 $\mu \mathrm{m}$.

Dados ecológicos: são macrófitas aquáticas que ocorrem enraizadas no substrato, com partes vegetativas inteiramente submersas ou emergentes, sendo também tolerantes à seca (Galvani \& Baptista, 2003).

Família Potamogetonaceae

Potamogeton L.

(Fig. 39)

Descrição: mônade, grão de pólen pequeno a médio, âmbito circular, esférico, tetraporado, exina grosseiramente reticulada com padrão irregular medindo aproximadamente $1,5 \mu \mathrm{m}$.

Dimensões ( 2 espécimes): diâmetro 22 e $28 \mu \mathrm{m}$.

Dados ecológicos: são macrófitas aquáticas que ocorrem enraizadas no substrato, com partes vegetativas inteiramente submersas. No PESP ocorrem quatro espécies: Potamogeton ferrugineus Hagstr, P. gayi A. Bernn., P. polygonus Chamess. \& Schltdl. e P. pusillus L. (Galvani \& Baptista, 2003).

Ordem Asparagales

Família Iridaceae

Sisyrinchium L.
(Fig. 40)

Descrição: mônade, grão de pólen médio, âmbito elíptico, subprolato, monosulcado com uma ectoabertura latitudinal (sulco) localizada num dos pólos; exina microrreticulada com $1,6 \mu \mathrm{m}$ de espessura.

Dimensões ( 2 espécimes): diâmetro polar 20 e 26 $\mu \mathrm{m}$, diâmetro equatorial 31 e $36 \mu \mathrm{m}$.

Dados ecológicos: herbácea com ocorrência no PESP registrada para a Savana Estépica Parque (Galvani \& Baptista, 2003).

\section{Comilenídeas}

Ordem Arecales

Família Arecaceae

tipo Butia Becc.

(Fig. 41)

Descrição: mônade, grão de pólen de tamanho médio a grande, bilateralmente simétricos, oblato, âmbito piriforme, monosulcado; exina com $2 \mu \mathrm{m}$ de espessura, microrreticulada; sexina e nexina de mesma espessura. Dimensões (10 espécimes): diâmetro equatorial maior entre 44 e $56 \mu \mathrm{m}$, diâmetro equatorial menor entre 27 e $36 \mu \mathrm{m}$.

Observações: distingue-se do tipo Syagrus romanzoffiana por apresentar um grão de pólen de maior tamanho (Bauermann et al., 2010). Material muito semelhante à "Arecaceae" descrito por Macedo et al. (2009). Dados ecológicos: são palmeiras, de estipe geralmente lenhoso, com distribuição predominantemente pantropical (Souza \& Lorenzi, 2008).

Ordem Commelinales

Família Commelinaceae

\section{Tradescantia L.}

(Fig. 42)

Descrição: mônade, grão de pólen de tamanho médio, âmbito elíptico, esférico, monosulcado, exina reticulada medindo $1,5 \mu \mathrm{m}$; sexina e nexina com a mesma espessura.

Dimensões (1 espécime): diâmetro equatorial maior $29 \mu \mathrm{m}$, diâmetro equatorial menor $23 \mu \mathrm{m}$.

Dados ecológicos: no PESP ocorre Tradescantia albiflora Kunth, espécie herbácea associada a borda da mata e interior da Mata Ciliar (Galvani \& Batista, 2003).

\section{Família Pontederiaceae}

\section{Pontederia L.}

(Fig. 43)

Descrição: mônade, grão de pólen de tamanho médio, âmbito elíptico, esférico, monosulcado, exina psilada; sexina e nexina com a mesma espessura.

Dimensões (1 espécime): diâmetro equatorial maior $54 \mu \mathrm{m}$.

Dados ecológicos: são macrófitas aquáticas que ocorrem enraizadas no substrato, com as partes vegetativas emergentes sendo também tolerantes a seca. No PESP ocorre a espécie Pontederia cordata L. (Galvani \& Baptista, 2003). 

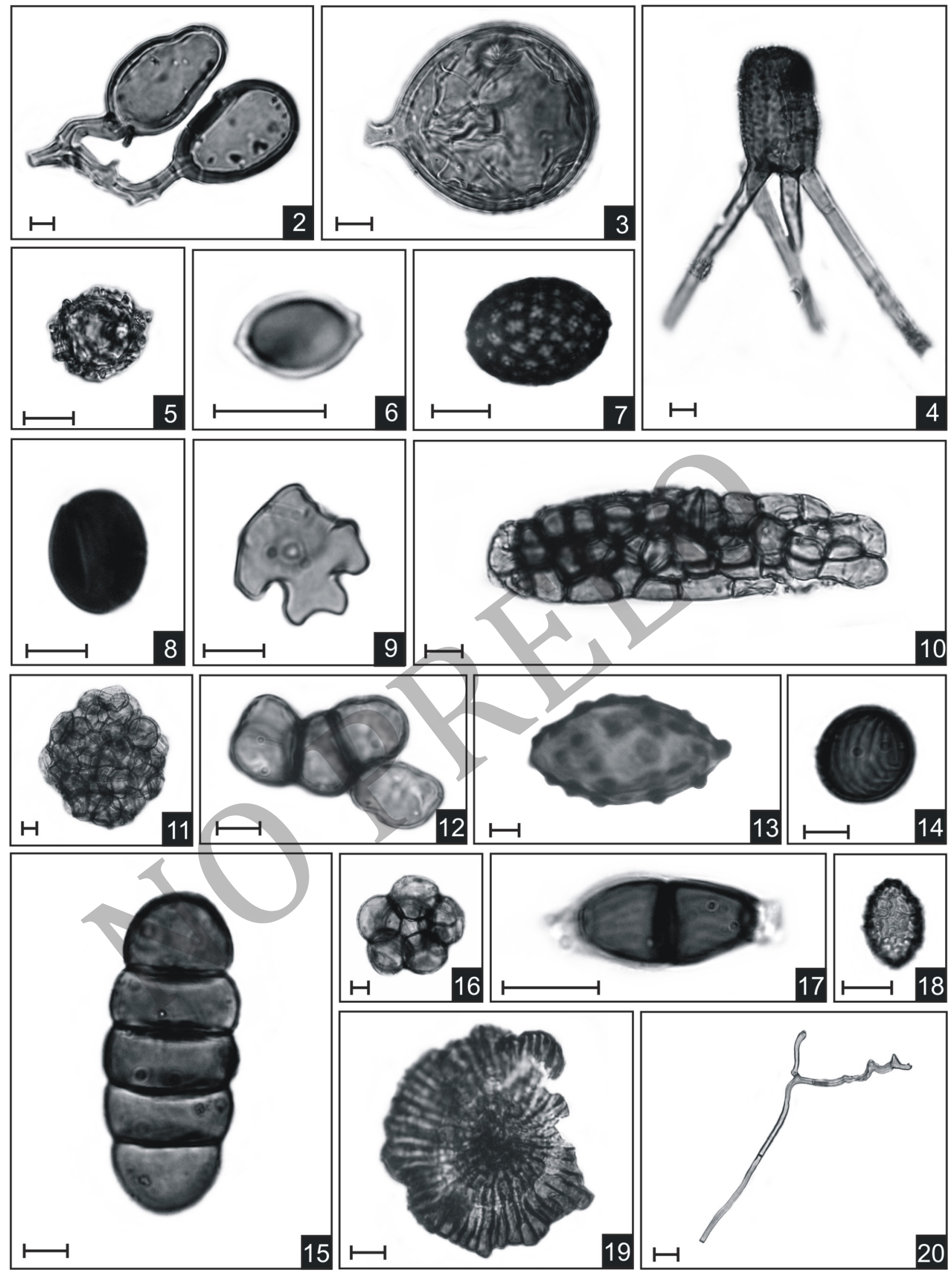

Figuras 2-20. Fotomicrografias de palinomorfos selecionados: 2-3. Glomus; 4. Tetraplosphaeria tetraploa; 5 . Bryophytomyces sphagni; 6. Ascósporo tipo Chaetomium; 7. Gelasinospora adjuncta; 8. Khuskia; 9. Gaeumannomyces cf. caricis; 10-18. Esporos indeterminados; 19. Frutificação de fungo; 20. Hifa de fungo. Escala gráfica correspondente a $10 \mu \mathrm{m}$. 

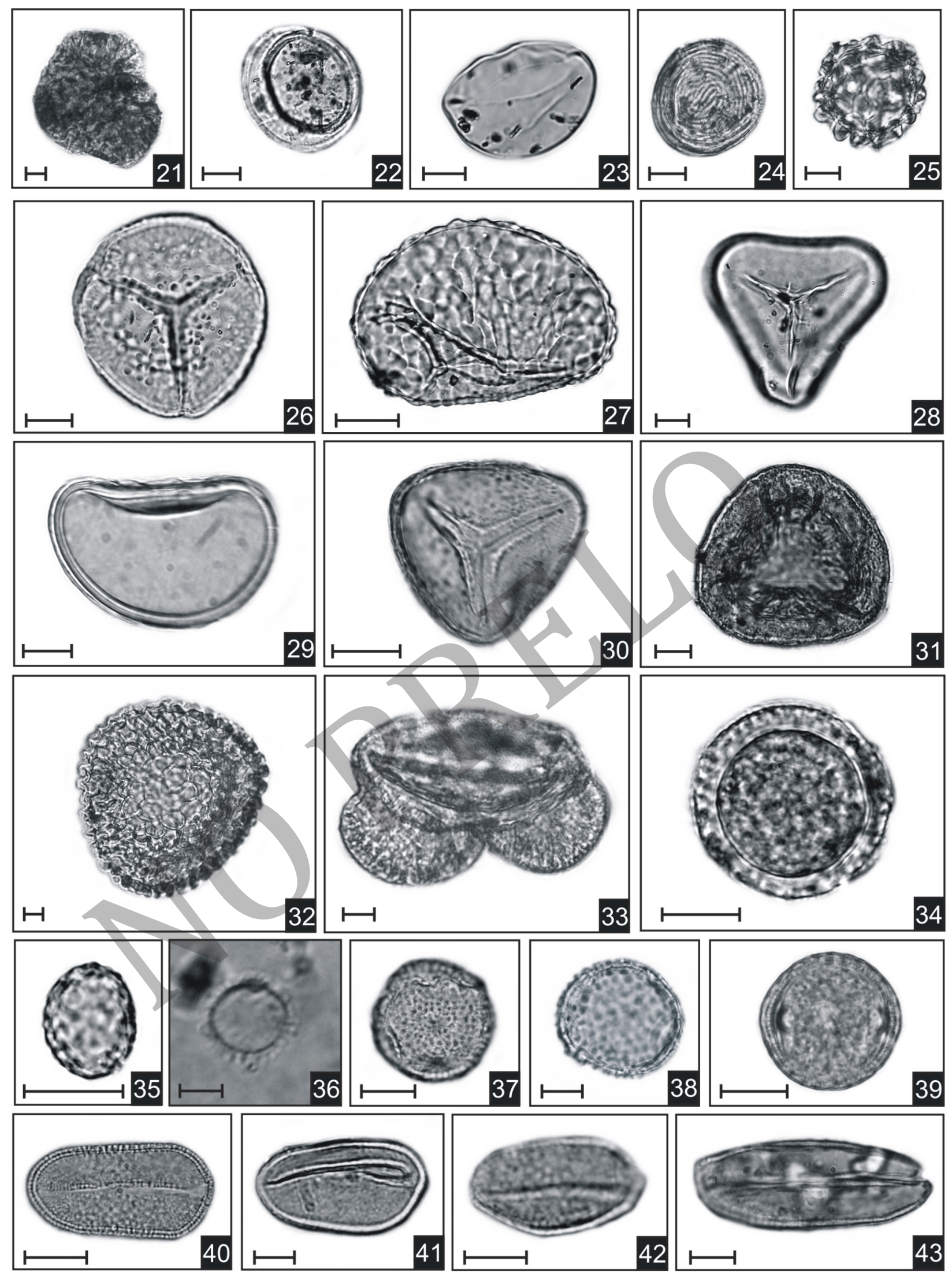

Figuras 21-43. Fotomicrografias de palinomorfos selecionados: 21. Botryococcus; 22. Debarya; 23. Spirogyra; 24. Pseudoschizaea rubina; 25. Bartramia; 26. Phaeoceros laevis; 27. tipo Microgramma vacciniifolia; 28. Cyatheaceae; 29. tipo Blechnum; 30. Adianthaceae; 31. Esporo trilete indeterminado 1; 32. Esporo trilete indeterminado 2; 33. Pinus; 34. Nectandra; 35. Peperomia; 36. Lemna; 37. Echinodorus grandiflorus; 38. Sagittaria montevidensis; 39. Potamogeton; 40. Sisyrinchium; 41. tipo Butia; 42. Tradescantia; 43. Pontederia. Escala gráfica correspondente a $10 \mu \mathrm{m}$. 
Ordem Poales

Família Bromeliaceae

\section{Tillandsia L.}

(Fig. 44)

Descrição: mônade, grão de pólen médio, âmbito eliptico, esférico, monosulcado, exina reticulada heterobrocada medindo até $1,5 \mu \mathrm{m}$ de espessura, retículos maiores no mesocolpo e menores no apocolpo; sexina e nexina com a mesma espessura.

Dimensões (25 espécimes): diâmetro equatorial maior entre 33 e $45 \mu \mathrm{m}$, diâmetro equatorial menor entre 20 e $29 \mu \mathrm{m}$.

Dados ecológicos: epífitas vasculares. No PESP ocorrem seis espécies: Tillandsia aeranthos (Loisel.) Smith, T. duratii Vis., T. geminiflora Broun, T. ixioides Griseb., T. recurvata (L.) L. e T. usneoides (L.) L., em ambientes de Savana Estépica Parque, borda e interior da Mata Ciliar (Galvani \& Baptista, 2003).

Família Bromeliaceae

\section{Eriocaulaceae}

(Fig. 45)

Descrição: mônade, grão de pólen de tamanho pequeno, isopolar, radiossimétrico, esferoidal, espiroaperturado; exina tectada medindo $2 \mu \mathrm{m}$, equinada, com pequenos e esparsos espinhos medindo aproximadamente $1 \mu \mathrm{m}$; entre os espinhos observam-se escabras em todo o grão; sexina com o dobro de espessura da nexina.

Dimensões (1 espécime): diâmetro $23 \mu \mathrm{m}$.

Dados ecológicos: herbácea heliófitas e higrófilas que ocorrem em banhados e campos úmidos (Cronquist, 1981).

Família Juncaceae

Juncaceae

(Fig. 46)

Descrição: mônade, grão de pólen de tamanho pequeno a médio, heteropolar, âmbito circular, esférico, inaperturado, exina escabrada ou microrreticulada.

Dimensões (18 espécimes): diâmetro entre 23 e $33 \mu \mathrm{m}$. Dados ecológicos: no PESP ocorre a espécie Juncus selowianus Kunth, uma erva que vegeta na Savana Estépica Parque e na borda da Mata Ciliar.

Família Cyperaceae

\section{Cyperaceae}

\section{(Fig. 47)}

Descrição: mônade, grão de pólen de tamanho pequeno a médio, heteropolares, radiossimétricos, prolato esferoidais a prolatos, monoporados no polo distal ou tritremados; polo distal mais largo que o proximal; podem apresentar de 1 a 3 sulcos paralelos ao diâmetro polar; sexina escabrada a granulada.

Dimensões (25 espécimes): diâmetro equatorial entre 22 e $36 \mu \mathrm{m}$.

Dados ecológicos: no PESP ocorrem 13 espécies de Cyperaceae que são associadas à vegetação herbácea da Savana Estépica Parque, borda da Mata Ciliar e banhado ou às macrófitas aquáticas enraizadas no substrato com tolerância à seca (Galvani \& Baptista, 2003).

Família Poaceae

\section{Poaceae}

Fig. 48

Descrição: mônade, grão de pólen de tamanho pequeno a médio, heteropolar, âmbito circular, esférico, monoporado, poro com ânulo, exina psilada, escabrada ou microrreticulada.

Dimensões (25 espécimes): diâmetro entre 30 e 65 m. Dados ecológicos: no PESP ocorrem 18 espécies de Poaceae que são associadas à vegetação herbácea preferencialmente da formação Savana Estépica Parque ou às macrófitas aquáticas enraizadas no substrato com tolerância à seca (Galvani \& Baptista, 2003).

\section{Eudicotiledôneas núcleo}

Ordem Caryophyllales

Família Amaranthaceae

\section{tipo Amaranthus L./Chenopodiaceae}

(Fig. 49)

Descrição: mônade, grão de pólen de tamanho médio, apolar, radiossimétrico, pantoporado (20 poros por face) esférico, circular; exina espessa (1,9 $\mu \mathrm{m})$, finamente escabrada; sexina com metade da espessura da exina.

Dimensões (3 espécimes): diâmetro entre 23 e 28 ㅆ. Dados ecológicos: no PESP ocorre a espécie Amaranthus quitensis H.B.K., erva associada à Savana Estépica Parque (Galvani \& Baptista, 2003).

\section{Froelichia tomentosa (Mart.) Moq.}

(Fig. 50)

Descrição: mônade, grão de pólen médio, apolar, radiossimétrico, âmbito circular, esférico, pantoporado, 12 poros observados em cada face, exina lofada medindo $1,8 \mu \mathrm{m}$; sexina mais espessa que nexina.

Dimensões (1 espécime): diâmetro $47 \mu \mathrm{m}$.

Dados ecológicos: no Brasil há registros para o município de Alegrete, ocorrendo também na Bahia, Argentina e Uruguai. Segundo Marchioretto et al. (2004), a espécie ocorre no Domínio Chaqueño e na Província do Espinal, que apresenta muitos elementos comuns com a Savana Estépica Parque.

\section{Pfaffia Mart.}

(Fig. 51)

Descrição: mônade, grão de pólen pequeno, apolar, radiossimétrico, âmbito circular, esférico, pantoporado, exina lofada; sexina mais espessa que nexina.

Dimensões (13 espécimes): diâmetro entre 33 e $37 \mu \mathrm{m}$. Dados ecológicos: no PESP ocorrem Pfaffia gnaphaloides (L.) Mart. e P. tuberosa (Spreng.) Hicken., ambas ervas associadas à Savana Estépica Parque (Galvani \& Baptista, 2003). 
Família Cactaceae

Opuntia Mill.

(Fig. 52)

Descrição: mônade, grão de pólen muito grande, apolar, âmbito circular, esférico, pantoporado, 16 poros (8 em cada face) medindo aproximadamente $18 \mu \mathrm{m}$ de diâmetro, exina reticulada medindo $4 \mu \mathrm{m}$ de espessura; columelas maiores nas regiões interporais; poros operculados.

Dimensões (2 espécimes): diâmetro 100 e $110 \mu \mathrm{m}$. Dados ecológicos: no PESP ocorre Opuntia bonaerensis Speg., de hábito arbustivo associado à Savana Estépica Parque (Galvani \& Baptista, 2003).

Família Polygonaceae

\section{Polygonum cf. hydropiperoides Michx.}

(Fig. 53)

Descrição: mônade, grão de pólen grande, âmbito circular, esférico, pantoporado, exina microreticulada medindo $5,5 \mu \mathrm{m}$.

Dimensões (11 espécimes): diâmetro entre 47 e $53 \mu \mathrm{m}$. Dados ecológicos: erva de ocorrência no PESP associada ao banhado ou à borda da Mata Ciliar (Galvani \& Baptista, 2003).

Ordem Santalales

Família Loranthaceae

Struthanthus Mart.

(Fig. 54)

Descrição: mônade, grão de pólen médio, âmbito triangular, oblato, tricolpado, sincolpado com colpos longos, exina reticulada medindo $2,9 \mu \mathrm{m}$; sexina mais espessa que nexina.

Dimensões (5 espécimes): diâmetro polar entre $20 \mathrm{e}$ $26 \mu \mathrm{m}$, diâmetro equatorial 32 e $37 \mu \mathrm{m}$.

Dados ecológicos: Durante as saídas a campo foi coletada a espécie Struthanthus uraguensis (Hook. et Arn.) G.Don (HERULBRA 4457). Com hábito lianescente, esta planta têm distribuição geográfica registrada no Uruguai, Paraguai e Brasil nos estados de MG, SP, RJ, PR, SC e RS (Reif \& Andreata, 2011).

Família Haloragaceae

\section{Myriophyllum L.}

(Fig. 55)

Descrição: mônade, grão de pólen pequeno, âmbito circular, suboblato, 4-5 brevicolpado, colpos com margo e ápices arredondados; exina escabrada medindo $1,5 \mu \mathrm{m}$ de espessura; sexina mais espessa que a nexina. Dimensões (7 espécimes): diâmetro polar 32 e $37 \mu \mathrm{m}$ entre diâmetro equatorial 18 e $20 \mu \mathrm{m}$.

Dados ecológicos: no PESP ocorre a espécie Myriophyllum aquaticum (Vell.) Verd.como macrófita aquática enraizada no substrato, com as partes vegetativas inteiramente submersas ou emergentes (Galvani \& Baptista, 2003).
Ordem Oxalidales

Família Oxalidaceae

\section{Oxalis L.}

(Fig. 56)

Descrição: mônade, grão de pólen médio, âmbito subtriangular, prolato esferoidal, tricolpado, colpos longos e com aproximadamente $2 \mu \mathrm{m}$ de largura, exina reticulada homobrocada medindo $1 \mu \mathrm{m}$ de espessura; sexina levemente mais espessa que a nexina.

Dimensões (6 espécimes): diâmetro polar entre 25 e $30 \mu \mathrm{m}$ e diâmetro equatorial entre 23 e $28 \mu \mathrm{m}$.

Dados ecológicos: no PESP ocorrem três espécies: Oxalis brasiliensis Lodd., O. perdicaria (Mol.) Bertero e Oxalis sellowianna Zucc., todas de hábito herbáceo e ocorrência associada à Savana Estépica Parque (Galvani \& Baptista, 2003).

Ordem Celastrales

Família Celastraceae

\section{Maytenus Molina}

(Fig. 57)

Descrição: mônade, grão de pólen pequeno, âmbito subtriangular, oblato esferoidal, tricolporado, exina (1 $\mu \mathrm{m})$ reticulada, homobrocada retículos medindo 1,9 $\mu \mathrm{m}$ de espessura; sexina mais espessa que a nexina.

Dimensões (3 espécimes): diâmetro polar entre 20 e $26 \mu \mathrm{m}$, diâmetro equatorial entre 20 e $29 \mu \mathrm{m}$.

Dados ecológicos: no PESP ocorre a espécie Maytenus ilicifolia Mart. ex Reiss., espécie arbórea que ocorre tanto na Savana Estépica Parque quanto na borda da Mata Ciliar (Galvani \& Baptista, 2003). Segundo Sobral et al. (2006) esta espécie ocorre, ainda que esporadicamente, em todas as formações florestais do Estado.

Ordem Malpighiales

Família Malpighiaceae

Janusia guaranitica (A.St.-Hil.) A.Juss.

(Fig. 58)

Descrição: mônade, grão de pólen médio, apolar, âmbito quadrangular, esférico, pantoporado apresentando 6 poros com colpoides ( 3 em cada face) distribuídos ao longo de toda a superfície do grão; poros circulares $4 \mu \mathrm{m}$ de diâmetro, 7 colpoides sendo 1 longo na região equatorial que divide o grão em duas metades e 6 curtos associados aos poros, livres ou fusionados entre si; exina psilada medindo $5 \mu \mathrm{m}$; sexina 4 vezes mais espessa que a nexina.

Dimensões (12 espécimes): diâmetro equatorial entre 45 e $48 \mu \mathrm{m}$.

Dados ecológicos: liana com ocorrência associada tanto na Savana Estépica Parque quanto na borda da Mata Ciliar (Galvani \& Baptista, 2003).

\section{Malpighiaceae}

(Fig. 59)

Descrição: mônade, grão de pólen médio, âmbito circular, esférico, porado com poros de difícil visualização, exina ornada medindo aproximadamente $5 \mu \mathrm{m}$. 
Dimensões (2 espécimes): diâmetro equatorial 40 e $46 \mu \mathrm{m}$. Dados ecológicos: a família possui distribuição tropical e subtropical. No Brasil ocorrem 45 gêneros e aproximadamente 300 espécies, de hábito principalmente herbáceo, podendo ser também árvores, arbustos ou lianas (Souza \& Lorenzi, 2008).

Família Euphorbiaceae

\section{Acalypha L.}

(Fig. 60)

Descrição: mônade, grão de pólen pequeno, âmbito circular, suboblatos, tricolporados, colpos de difícil visualização, muito curtos e inconspícuos (somente visíveis em aumento de $1000 \mathrm{x}$ ), poros com áspide, exina finamente escabrada medindo $1 \mu \mathrm{m}$ de espessura; sexina levemente mais espessa que a nexina.

Dimensões (3 espécimes): diâmetro polar entre 10 e $13 \mu \mathrm{m}$, diâmetro equatorial entre 12 e $15 \mu \mathrm{m}$.

Dados ecológicos: a família Euphorbiaceae está estre as mais comuns nas formações naturais brasileiras. Espécies do gênero Acalypha, são ervas utilizadas como ornamentais (Souza \& Lorenzi, 2008).

\section{Euphorbiaceae}

(Fig. 61)

Descrição: mônade, grão de pólen médio, âmbito subtriagular, subprolato, tricolporados, colpos longos com ápices afilados, exina reticulada.

Dimensões (25 espécimes): diâmetro polar entre 25 e $33 \mu \mathrm{m}$, diâmetro equatorial entre 22 e $27 \mu \mathrm{m}$.

Dados ecológicos: Euphorbiaceae estão entre as famílias mais comuns nas formações naturais brasileiras e é uma das mais complexas do ponto de vista taxonômico (Souza \& Lorenzi, 2008). No PESP ocorrem principalmente espécies de hábito arbóreo associadas à Mata Ciliar (Galvani \& Baptista, 2003).

\section{Sebastiania Spreng.}

(Fig. 62)

Descrição: mônade, grão de pólen médio, âmbito subtriangular, prolato esferoidal, tricolporado, colpos longos com margo, endoabertura lalongada, exina microreticulada medindo $2 \mu \mathrm{m}$ de espessura.

Dimensões (5 espécimes): diâmetro polar entre 30 e $40 \mu \mathrm{m}$, diâmetro equatorial entre 26 e $34 \mu \mathrm{m}$.

Dados ecológicos: no PESP ocorre a espécie Sebastiania commersonia (Baillon.) L.B. Smith. De hábito arbóreo esta espécie está sempre associada à Mata Ciliar ou ao banhado (Galvani \& Baptista, 2003).

Família Passifloraceae

Passiflora (sp. 1)

(Fig. 63)

Descrição: mônade, grão de pólen grande, subprolato, âmbito subcircular, 12-colporado, colpos curtos e estreitos distribuídos aos pares com um opérculo para cada par de colpos, poro de difícil visualização; exina expessa $(5 \mu \mathrm{m})$, semitectada, reticulada heterobroca- da, muros simples, columelados, lisos e sinuosos com báculos livres (de difícil visualização) no interior dos lúmens.

Dimensões (10 espécimes): diâmetro polar entre 54 e $56 \mu \mathrm{m}$, diâmetro equatorial entre 43 e $46 \mu \mathrm{m}$.

Observações: compatível com a descrição de Passiflora Grupo II de Evaldt et al. (2011).

Dados ecológicos: Passiflora é o principal gênero de Passifloraceae, ocorrendo 140 espécies no Brasil, 15 espécies no Rio Grande do Sul. São lianas que podem ocorrem em todas as regiões fisiográficas do Estado estão associadas às formações florestais e campestres (Mondin et al., 2011).

\section{Passiflora (sp. 2)}

(Fig. 64)

Descrição: mônade, grão de pólen grande, isopolar, radiossimétrico, esférico, âmbito circular, 6-sincolpado, colpos longos distribuídos aos pares, unindo-se longitudinalmente nas extremidades formando um anel ao redor do pseudopérculo, sincolpos distribuídos regularmente ao longo de todo o grão de pólen; exina espessa $(5 \mu \mathrm{m})$, semitectada, reticulada heterobrocada com muros simples, columelados, lisos sinuosos e com báculos livres no interior dos lúmens.

Dimensões (1 espécimes): diâmetro $63 \mu \mathrm{m}$.

Observações: compatível com a descrição de Passiflora Grupo I de Evaldt et al. (2011) que inclui a espécie Passiflora caerulea $\mathrm{L}$.

Dados ecológicos: no PESP ocorre a espécie Passiflora caerulea L., liana associada tanto à Mata Ciliar quanto à savana Estépica Parque (Galvani \& Baptista, 2003).

\section{Família Salicaceae}

\section{Salix humboldtiana Willd.}

(Fig. 65)

Descrição: mônade, grão de pólen pequeno, âmbito subtriangular, prolato, tricolporado; exina reticulada heterobrocada com lúmens maiores na região equatorial dos mesocolpos; sexina mais espessa que a nexina. Dimensões (6 espécimes): diâmetro polar entre 21 e $25 \mu \mathrm{m}$, diâmetro equatorial entre 15 e $19 \mu \mathrm{m}$.

Dados ecológicos: ocorre desde o México até o sul da América do Sul. No Rio Grande do Sul ocorre em todas as formações florestais ribeirinhas do Estado (Sobral et al., 2006). No PESP a espécie é citada como macrófita aquática tolerante à seca (Galvani \& Baptista, 2003).

\section{Ordem Fabales}

Família Fabaceae

\section{Caesalpinia L.}

(Fig. 66)

Descrição: mônade, grão de pólen tricolporado, âmbito subtriangular, prolato esferoidal, sincolpado, colpos longos, endoabertura lalongada, exina reticulada heterobrocada medindo $2 \mu \mathrm{m}$ de espessura; sexina e nexina de mesma espessura.

Dimensões ( 2 espécimes): diâmetro polar 52 e 57 
$\mu \mathrm{m}$, diâmetro equatorial 51 e $55 \mu \mathrm{m}$.

Dados ecológicos: no PESP ocorrem espécies desta subfamília na Savana Estépica Parque e na Mata Ciliar (Galvani \& Baptista, 2003; Souza \& Lorenzi, 2008).

\section{Erythrina L.}

(Fig. 67)

Descrição: mônade, grão de pólen médio, âmbito subtriangular, oblato, triporado, exina reticulada heterobrocada.

Dimensões (2 espécimes): diâmetro equatorial $31 \mathrm{e}$ $35 \mu \mathrm{m}$.

Dados ecológicos: no PESP ocorre a espécie Erythrina crista-galli L., registrada como macrófita aquática tolerante à seca (Galvani \& Baptista, 2003). A espécie tem ocorrência registrada para Argentina, Bolívia, Paraguai e Brasil, do Maranhão ao Rio Grande do Sul, habitando locais muito úmidos, em florestas ribeirinhas e várzeas inundáveis (Sobral et al., 2006).

\section{Fabaceae}

(Fig. 68)

Descrição: mônade, grão de pólen de tamanho pequeno, âmbito subtriangular, prolato, tricolporado, colpos longos, endoabertura lolongada, poro esférico, exina reticulada nos mesocolpos e psilada na região das aberturas; sexina e nexina de mesma espessura.

Dimensões (25 espécimes): diâmetro equatorial en tre 21 e $23 \mu \mathrm{m}$.

Dados ecológicos: a família tem distribuição pantropical, no Brasil ocorrem 175 gêneros e 1500 espécies. São ervas, arbustos, árvores ou lianas. Na maioria dos ecossistemas naturais brasileiros, Fabaceae está incluída entre as principais famílias (Souza \& Lorenzi, 2008). No PESP ocorrem 25 espécies de hábitos variados em ambientes associados tanto a Mata Ciliar quanto à Savana Estépica Parque (Galvani \& Baptista, 2003).

\section{Mimosoideae}

(Fig. 69)

Descrição: políade formada por 32 grãos de pólen (16 em cada face), âmbito elíptico, esférica, grãos de pólen tricolporadas, exina psilada medindo $1,5 \mu \mathrm{m}$.

Dimensões (25 espécimes): diâmetro entre 43 e $47 \mu \mathrm{m}$. Dados ecológicos: no PESP ocorrem espécies desta subfamília na Savana Estépica Parque e na Mata Ciliar, incluindo as espécies características da Savana Estépica Parque de hábito arbóreo e herbáceo (Galvani \& Baptista, 2003; Souza \& Lorenzi, 2008).

\section{Parkinsonia aculeata L.}

(Fig. 70)

Descrição: mônade, grão de pólen médio, âmbito subtriangular, subprolato, tricolporado, endoabertura lalongada, exina reticulada heterobrocada medindo 2 $\mu \mathrm{m}$; sexina mais espessa que a nexina.

Dimensões (25 espécimes): diâmetro polar $28 \mu \mathrm{m}$, diâmetro equatorial $23 \mu \mathrm{m}$.
Dados ecológicos: árvore que ocorre no Brasil desde o Nordeste até o Rio Grande do Sul, onde cresce em campos secos do sudoeste do Estado (Sobral et al., 2006). No PESP tem ocorrência associada à borda e interior da Mata Ciliar (Galvani \& Baptista, 2003).

\section{Prosopis L.}

(Fig. 71)

Descrição: mônade, grão de pólen pequeno a médio, âmbito subtriangular, prolato, tricolporado, colpos longos constrito no equador, poro esférico, exina psilada medindo 1,5 $\mu \mathrm{m}$; sexina e nexina de mesma espessura. Dimensões (25 espécimes): diâmetro polar entre 26 e $35 \mu \mathrm{m}$, diâmetro equatorial entre 17 e $25 \mu \mathrm{m}$.

Dados ecológicos: no PESP ocorrem duas espécies, Prosopis affinis Spreng. e P. nigra (Griseb) Hieron, ambas arvores características da Savana Estépica Parque (Galvani \& Baptista, 2003).

\section{Vachellia caven (Molina) Seigler \& Ebinger}

(Figs. 72-73)

Descrição: políade formada por 32 grãos de pólen $(16$ em cada face), âmbito eliptico, esférica, co-aperturada, grãos de pólen medindo entre 14 e $16 \mu \mathrm{m}$ apresentando aberturas sincolpadas formando uma marca característica, exina microrreticulada medindo $1,5 \mu \mathrm{m}$.

Dimensões (25 espécimes): diâmetro entre 50 e $55 \mu \mathrm{m}$. Observações: espécie anteriormente denominada Acacia caven.

Dados ecológicos: juntamente com Prosopis affinis e P. nigra, esta árvore caracteriza a associação da Savana Estépica Parque (Galvani \& Baptista, 2003).

Família Polygalaceae

Polygalaceae

(Fig. 74)

Descrição: mônade, grão de pólen médio, âmbito circular, prolato esferoidal, 14 estefanocolporado, colpos longos endocingulados; exina psilada com perfurações que se concentram principalmente em vista polar; nexina mais espessa que a sexina.

Dimensões (25 espécimes): diâmetro polar 43 e 57 $\mu \mathrm{m}$, diâmetro equatorial 38 e $45 \mu \mathrm{m}$.

Dados ecológicos: planta herbácea encontrada em áreas abertas (Souza \& Lorenzi, 2008). No PESP ocorrem duas espécies, Polygala campestris Gardner e Polygala paniculata L., ambas ervas de ocorrência associada à borda da Mata Ciliar (Galvani \& Baptista, 2003).

Ordem Rosales

Família Rosaceae

\section{Rosaceae}

(Fig. 75)

Descrição: mônade, grão de pólen médio, âmbito subtriangular, prolato esferoidal, tricolporado, colpo com margo, endoabertura lalongada, exina estriada medindo $2 \mu \mathrm{m}$ com estrias de $1 \mu \mathrm{m}$ mais evidentes nos pólos; sexina menos espessa que a nexina. 

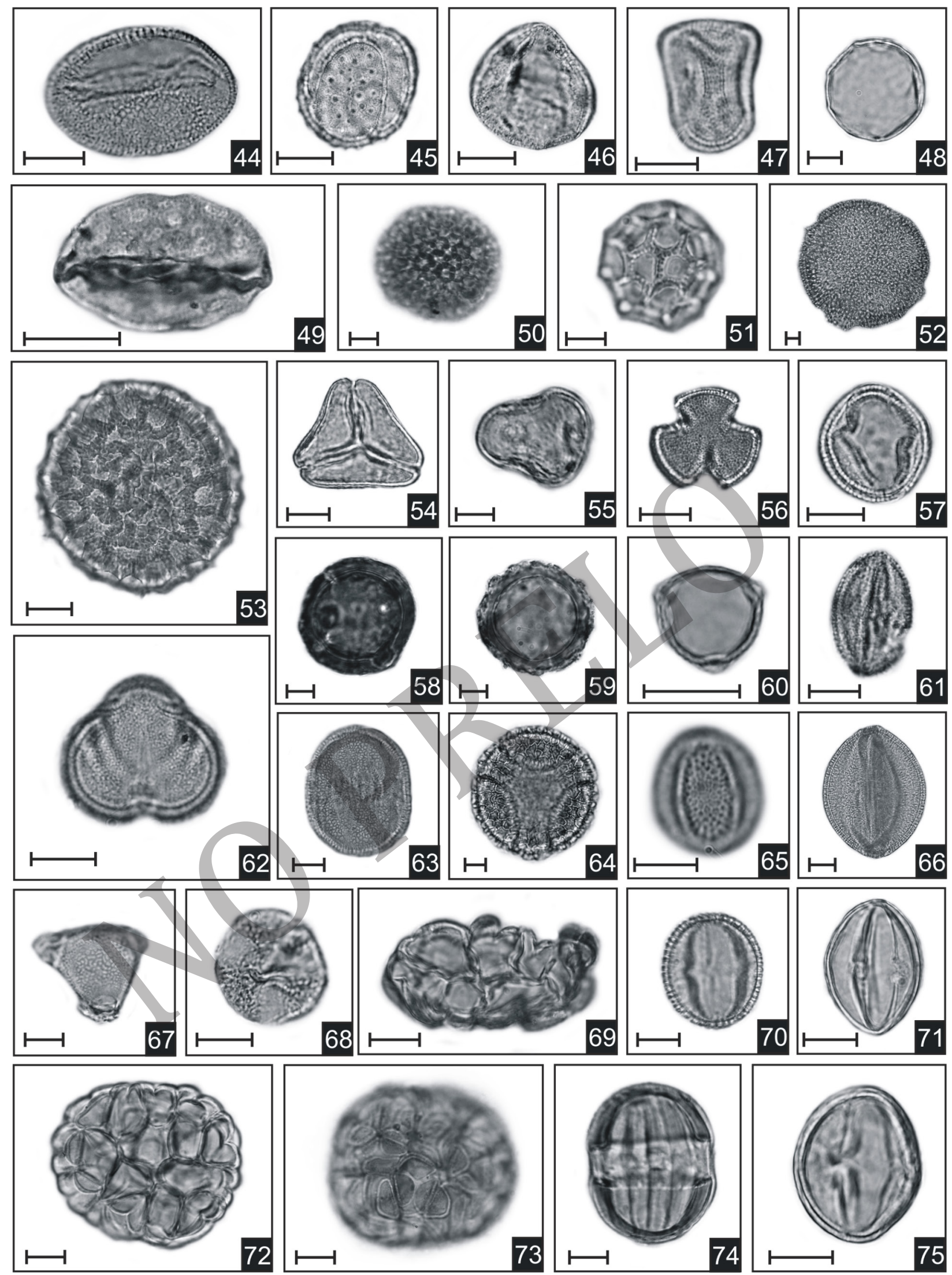

Figuras 44-75. Fotomicrografias de palinomorfos selecionados: 44. Tillandsia; 45. Eriocaulaceae; 46. Juncaceae; 47. Cyperaceae; 48. Poaceae; 49. tipo Amaranthus L./Chenopodiaceae; 50. Froelichia tomentosa; 51. Pfaffia; 52. Opuntia; 53. Polygonum cf. hydropiperoides; 54. Struthanthus; 55. Myriophyllum; 56. Oxalis; 57. Maytenus; 58. Janusia guaranitica; 59. Malpighiaceae; 60. Acalypha; 61 . Euphorbiaceae; 62. Sebastiania; 63. Passiflora (sp. 1); 64. Passiflora (sp. 2); 65. Salix humboldtiana; 66. Caesalpinia; 67. Erythrina; 68. Fabaceae; 69. Mimosoideae; 70. Parkinsonia aculeata; 71. Prosopis; 72-73. Vachellia caven, 74. Polygalaceae; 75. Rosaceae. Escala gráfica correspondente a 10 um. 
Dimensões (1 espécime): diâmetro polar 25 m, diâmetro equatorial $24 \mu \mathrm{m}$.

Dados ecológicos: é uma das maiores famílias de Angiospermas, com distribuição cosmopolita concentrada no Hemisfério Norte, ocorrendo oito gêneros no Brasil e cerca de 25 espécies (Souza \& Lorenzi, 2008).

Família Cannabaceae

\section{Celtis L.}

(Fig. 76)

Descrição: mônade, grão de pólen pequeno, âmbito circular, suboblato, triporado, exina escabrada medindo $2 \mu \mathrm{m}$ de espessura; sexina mais espessa que a nexina. Dimensões (25 espécimes): diâmetro polar entre 18 e $24 \mu \mathrm{m}$, diâmetro equatorial entre 23 e $27 \mu \mathrm{m}$.

Observações: descrição compatível com a espécie $\mathrm{Cel}$ tis iguanea (Evaldt et al., 2009).

Dados ecológicos: no PESP ocorre a espécie Celtis tala Gillies associada à Savana Estépica Parque e a borda da Mata Ciliar (Galvani \& Baptista, 2003). Árvore também registrada no RS para Depressão Central, em Santa Maria e Lavras do Sul (Backes \& Nardino, 2003).

\section{Trema micrantha (L.) Blume}

\section{(Fig. 77)}

Descrição: mônade, grão de pólen pequeno, âmbito circular, oblato esferoidal, diporado ocasionalmente triporado, exina escabrada medindo $1 \mu \mathrm{m}$ de espessura; sexina mais espessa que a nexina.

Dimensões (7 espécimes): diâmetro polar entre 17 $20 \mu \mathrm{m}$, diâmetro equatorial entre 18 e $21 \mu \mathrm{m}$.

Dados ecológicos: ocorre na América Central e do Sul. No Brasil é encontrada em todas as regiões do país, sendo comum em todas as formações florestais do Rio Grande do Sul (Sobral et al., 2006).

Família Moraceae

\section{Dorstenia L.}

(Fig. 78)

Descrição: mônade, grão de pólen pequeno, esférico, pantoporados com 10 a 12 poros pequenos elipsoidais por grão; exina granulada.

Dimensões (20 espécimes): diâmetro entre 19 e $23 \mu \mathrm{m}$. Dados ecológicos: no PESP ocorre a espécie Dorstenia brasiliensis Lam., erva de ocorrência associada à Savana Estépica Parque (Galvani \& Baptista, 2003).

\section{Moraceae/ Urticaceae}

(Fig. 79)

Descrição: mônade, grão de pólen pequeno, âmbito subcircular, suboblato, diporado. Exina com espículos de difícil visualização, sexina mais espessa que a nexina. Dimensões (25 espécimes): diâmetro polar entre $9 \mathrm{e}$ $12 \mu \mathrm{m}$, diâmetro equatorial entre 12 e $16 \mu \mathrm{m}$.

Dados ecológicos: são preferencialmente ervas podendo ser também árvores, arbustos e lianas. Comuns nos ecossistemas naturais brasileiros (Souza \& Lorenzi, 2008).

\section{Sorocea bonplandii (Baill.) W.C.Burger}

(Fig. 80)

Descrição: mônade, grão de pólen pequeno, âmbito subcircular, suboblato, triporado, poros providos de áspide e operculados. Exina granulada, sexina mais espessa que a nexina.

Dimensões ( 2 espécimes): diâmetro polar 11 e 15 $\mu \mathrm{m}$, diâmetro equatorial 12 e $16 \mu \mathrm{m}$.

Dados ecológicos: árvore de até $15 \mathrm{~m}$ de altura, com ocorrência registrada do Pernambuco ao Rio Grande do Sul, em formações florestais (Backes \& Nardino, 2003).

Ordem Fagales

Família Fagaceae

\section{Nothofagus Blume}

(Fig. 81)

Descrição: mônade, grão de pólen médio, âmbito circular, oblatos, estefanocolpado, colpos curtos e de ápices arredondados, com margo; exina microequinada com espinhos regularmente distribuídos e estratificação obscura.

Dimensões (15 espécimes): diâmetro equatorial entre 29 e $35 \mu \mathrm{m}$.

Dados ecológicos: táxon exótico. Fagaceae tem distribuição predominantemente no Hemisfério Norte, Andes e Oceania (Souza \& Lorenzi, 2008).

Ordem Myrtales

Família Lythraceae

Cuphea P. Browne

(Fig. 82)

Descrição: mônade, grão de pólen pequeno, âmbito triangular, suboblato, tricolporado, colpos longos com endoabertura lalongada, exina estriada; nexina mais espessa que sexina.

Dimensões (4 espécimes): diâmetro polar entre 16 e $20 \mu \mathrm{m}$, diâmetro polar entre 21e $24 \mu \mathrm{m}$.

Dados ecológicos: no PESP ocorre Cuphea sp., erva que vegeta a Savana Estépica Parque e a borda da Mata Ciliar (Galvani \& Baptista, 2003).

\section{Heymia Link.}

(Fig. 83)

Descrição: mônade, grão de pólen pequeno, âmbito subtriangular, subprolato, tricolporado colpos longos e cobertos por membrana granular, endoabertura circular com fastígio exina levemente reticulada.

Dimensões (5 espécimes): diâmetro polar entre 22 e $24 \mu \mathrm{m}$, diâmetro equatorial entre17 e $19 \mu \mathrm{m}$.

Dados ecológicos: no PESP ocorre a espécie Heimia salicifolia Link \& Otto, arbusto de ocorrência associada à Savana Estépica Parque (Galvani \& Baptista, 2003). Ocorre no RS e SC em áreas pioneiras de origem fluvial (Backes \& Nardino, 2003).

\section{Família Onagraceae}

Onagraceae L.

(Fig. 84) 
Descrição: mônade, grão de pólen grande, âmbito triangular, suboblatos, triporados, com membrana apertural; poros com fastígio; exina verrucada.

Dimensões (2 espécimes): diâmetro equatorial 57 e $62 \mu \mathrm{m}$. Dados ecológicos: no PESP ocorrem duas espécies herbáceas Ludwigia grandiflora (Michx.) Zard., Gu \& Haven e L. longifolia (DC.) Hara, ambas consideradas macrófitas aquáticas tolerantes à seca (Galvani \& Baptista, 2003).

Família Combretaceae

\section{Combretum fruticosum (Loefl.) Stuntz}

(Fig. 85)

Descrição: mônade, grão de pólen pequeno, âmbito circular, prolato esferoidal, tricolporado, heterocolpado sendo 3 colpos com os lalongado e 3 pseudocolpos, exina aparentemente psilada, mas levemente reticulada medindo $1,5 \mu \mathrm{m}$; nexina levemente mais espessa que a sexina.

Dimensões (11 espécimes): diâmetro polar entre 18 e $22 \mu \mathrm{m}$, diâmetro equatorial entre 20 e $25 \mu \mathrm{m}$.

Dados ecológicos: liana lenhosa que ocorre no RS e SC sempre associada às formações florestais (Backes \& Nardino, 2003).

Família Myrtaceae

\section{Myrtaceae}

(Fig. 86)

Descrição: mônade, grãos de pólen pequenos, heteropolares, âmbito triangular, oblatos, trisincolporados, colpos longos e anastomosados nos pólos, formando um pequeno triângulo no apocolpo, endoabertura com fastígio, aparentemente circular, exina escabrada medindo $1 \mu \mathrm{m}$ de espessura; sexina levemente menos espessa que a nexina.

Dimensões (25 espécimes): diâmetro equatorial entre 20 e $25 \mu \mathrm{m}$.

Dados ecológicos: no PESP são registradas nove espécies de hábito arbóreo ou arbustivo que ocorrem na borda ou interior da Mata Ciliar (Galvani \& Baptista, 2003).

\section{Eurosídeas II}

Ordem Brassicales

Família Brassicaceae

\section{Raphanus L.}

(Fig. 87)

Descrição: mônade, grão de pólen médio, âmbito subtriangular, subprolato, tricolpado, exina reticulada medindo $2 \mu \mathrm{m}$ de espessura.

Dimensões (2 espécimes): diâmetro polar entre 28 e $32 \mu \mathrm{m}$, diâmetro equatorial entre 23 e $26 \mu \mathrm{m}$.

Dados ecológicos: gênero introduzido no Brasil que ocorre de forma subespontânea (Souza \& Lorenzi, 2008).

Ordem Malvales

Família Malvaceae

Sida cf. rhombifolia $\mathrm{L}$.

(Figs. 88-89)

Descrição: mônade, grão de pólen grande, âmbito cir- cular, esférico, pantoporado, exina equinada medindo 6 $\mu \mathrm{m}$ de espessura; espinhos grandes $(6 \mu \mathrm{m})$ com ápices atenuados e bases largas associadas à microespinhos em torno da base; sexina mais espessa que a nexina; columelas delgadas, longas e distribuídas de forma irregular, sendo maiores na região abaixo do espinho.

Dimensões (25 espécimes): diâmetro entre 92 e $97 \mu \mathrm{m}$. Dados ecológicos: erva que ocorre no PESP associada à Savana Estépica Parque e à borda da Mata Ciliar (Galvani \& Baptista, 2003).

Ordem Sapindales

Família Anacardiaceae

\section{Anacardiaceae}

(Fig. 90)

Descrição: mônade, grão de pólen médio, âmbito subtriangular, tricolporado, colpos longos com margo, exina reticulada-estriada com estrias não organizadas medindo $1,5 \mu \mathrm{m}$; sexina mais espessa que a nexina.

Dimensões (1 espécime): diâmetro polar $23 \mu \mathrm{m}$, diâmetro equatorial $29 \mu \mathrm{m}$.

Dados ecológicos: arbustos ou árvores (Souza \& Lorenzi, 2008). No PESP ocorrem de Lithraea molleoides (Vell.) Engl. e Schinus terebinthifolius Marchand, cujo hábitat está associado à borda de mata e interior de mata, respectivamente (Galvani \& Baptista, 2003). A distribuição geográfica de Lithraea molleoides é Argentina, Bolívia, Paraguai, Uruguai e Brasil, do Mato Grosso e Bahia até o Rio Grande do Sul. Para Schinus terebinthifolius a distribuição geográfica registrada é Argentina, Paraguai, Uruguai, Venezuela e no Brasil do Piauí ao Rio Grande do Sul (Sobral et al., 2006).

Família Sapindaceae

Sapium P. Browne

(Fig. 91)

Descrição: mônade, grão de pólen médio, âmbito subtriangular, prolato, tricolporado, colpos longos com margo que se espessa junto ao poro, endoabertura lalongada, exina microrreticulada medindo aproximadamente $3 \mu \mathrm{m}$ com lúmens maiores nos polos e menores no equador; sexina com o dobro da nexina.

Dimensões (3 espécimes): diâmetro polar entre 45 e $50 \mu \mathrm{m}$, diâmetro equatorial entre 30 e $35 \mu \mathrm{m}$.

Dados ecológicos: árvores de mais de $13 \mathrm{~m}$ de altura com ocorrência registrada no RS para formações florestais e campestres (Backes \& Nardino, 2003).

\section{Clado Asterideas}

Ordem Ericales

Família Sapotaceae

Chrysophyllum L.

(Fig. 92)

Descrição: mônade, grão de pólen médio, isopolar, âmbito circular, tricolporado, exina psilada mais espessa nos polos.

Dimensões ( 2 espécimes): diâmetro polar 27 e 30 $\mu \mathrm{m}$, diâmetro equatorial 13 e $18 \mu \mathrm{m}$. 
Dados ecológicos: no PESP ocorre a espécie Chrisophyllum marginatum (Hook. \& Arn.) Radlk. na borda e interior da Mata Ciliar (Galvani \& Baptista, 2003). São árvores ou arbustos de até $15 \mathrm{~m}$ de altura com distribuição registrada desde a Bahia ao RS (Backes \& Nardino, 2003).

Família Myrsinaceae

Myrsine L.

(Fig. 93)

Descrição: mônade, grão de pólen pequeno, isopolar, âmbito subquadrangular, tetracolpado, exina levemente escabrada.

Dimensões (1 espécime): diâmetro equatorial $23 \mu \mathrm{m}$. Dados ecológicos: de hábito arbóreo e arbustivo, constituem espécies pioneiras, formadoras de florestas diretamente sobre o campo, com boa regeneração em vegetação secundária (Backes \& Irgang, 2002).

\section{Ericaceae}

(Fig. 94)

Descrição: tétrade tetraédrica, calimada, coaperturada, em que os grãos de pólen contíguos têm aberturas unidas, formando pares em seis pontos da tétrade, endoabertura lalongada, exina escabrada, 2,5 $\mu \mathrm{m}$ de espessura; sexina mais espessa que a nexina.

Dimensões (1 espécime): diâmetro da tétrade $40 \mu \mathrm{m}$. Dados ecológicos: a maioria das espécies ocorre no Brasil em áreas de maior altitude, entretanto existem espécies como Gaylussacia brasiliensis que ocorrem em áreas alagáveis, desde grandes altitudes até o nível do mar (Souza \& Lorenzi, 2008).

Ordem Solanales

Família Solanaceae

Solanum L.

(Fig. 95)

Descrição: mônade, grão de pólen médio, âmbito circular, oblato esferoidal, tricolporado, colpos longos com membrana proeminente no poro, endoabertura lalongada com margem não delimitada, exina psilada medindo $1 \mu \mathrm{m}$ de espessura; sexina mais espessa que a nexina.

Dimensões (3 espécimes): diâmetro polar entre 24 e $31 \mu \mathrm{m}$, diâmetro equatorial entre 17 e $22 \mu \mathrm{m}$.

Dados ecológicos: no PESP ocorrem duas espécies, Solanum americanum Mill. e S. commersonii Dunal, ervas que vegetam preferencialmente na Savana Estépica Parque (Galvani \& Baptista, 2003).

\section{Família Boraginaceae}

\section{Echium plantagineum $\mathrm{L}$.}

\section{(Fig. 96)}

Descrição: mônade, grão de pólen pequeno, âmbito subtriangular, heteropolar, prolato, tricolporado, endoabertura circular, colpos longos, exina levemente microrreticulada medindo $1 \mu \mathrm{m}$ de espessura.

Dimensões (12 espécimes): diâmetro polar entre 18 e $20 \mu \mathrm{m}$, diâmetro equatorial entre 13 e $18 \mu \mathrm{m}$.

Dados ecológicos: a família Boraginaceae ocorre em re- giões temperada e tropical; no Brasil ocorre 12 gêneros e cerca de 100 espécies (Souza \& Lorenzi, 2008). Embora não tenha ocorrência registrada no levantamento botânico, a espécie foi coletada em saída a campo, posteriormente depositada no Herbário da ULBRA (HERULBRA 4330).

Ordem Gentianales

Família Apocynaceae

\section{Aspidosperma quebracho-blanco Schltdl.}

(Fig. 97)

Descrição: mônade, grão de pólen médio, âmbito circular, oblato esferoidal, heterocolpado sendo quatro colpos longos com ós lalongado e quatro pseudocolpos, exina microrreticulada medindo $3 \mu \mathrm{m}$ de espessura.

Dimensões (21 espécimes): diâmetro polar entre 29 e $33 \mu \mathrm{m}$, diâmetro equatorial entre 31 e $34 \mu \mathrm{m}$.

Dados ecológicos: de hábito arbóreo, Aspidosperma quebracho-blanco é uma das espécies que caracteriza a Savana Estépica Parque (Galvani \& Baptista, 2003).

Ordem Lamiales

Família Plantaginaceae

\section{Plantago L}

(Fig. 98)

Descrição: mônade, grão de pólen pequeno, âmbito circular, esférico, pantoporado (10 poros); exina tectada $(1,1 \mu \mathrm{m})$, verrucada e com columelas indistintas; poros circulares medindo $2 \mu \mathrm{m}$ de diâmetro ou $3 \mu \mathrm{m}$ se contado juntamente com o ânulo; verrugas mais ou menos circulares medindo de 2 a $3 \mu \mathrm{m}$; sexina e nexina de mesma espessura.

Dimensões (4 espécimes): diâmetro entre 22 e 25 m. Dados ecológicos: as Plantaginaceae são mais comuns em áreas abertas, nos campos sulinos e em áreas periodicamente inundadas da caatinga (Souza \& Lorenzi, 2008). No PESP ocorrem uma espécie, Plantago tomentosa Lam., erva de ocorrência restrita à Savana Estépica Parque (Galvani \& Baptista, 2003).

\section{Scoparia L.}

(Fig. 99)

Descrição: mônade, grão de pólen pequeno, âmbito subcircular, subprolato, tricolporado, colpos com margo, endoabertura lalongada; exina microrreticulada medindo $1 \mu \mathrm{m}$ de espessura.

Dimensões (2 espécimes): diâmetro polar 13 e 15 $\mu \mathrm{m}$, diâmetro equatorial 11 e $13 \mu \mathrm{m}$.

Dados ecológicos: Scoparia é uma erva de ocorrência preferencial em áreas abertas dos campos sulinos (Souza \& Lorenzi, 2008).

\section{Família Acanthaceae}

\section{Justicia laevilinguis (Nees) Lindau}

(Fig. 100)

Descrição: mônade, grão de pólen pequeno, âmbito circular, prolato, dicolporado, colpos curtos estreitos e de difícil observação; endoabertura lalongada bem evidente; exina microrreticulada medindo $2 \mu \mathrm{m}$ de espes- 
sura; nexina mais espessa que a sexina no pólo e sexina mais espessa que a nexina no equador.

Dimensões (9 espécimes): diâmetro polar entre 19 e $27 \mu \mathrm{m}$, diâmetro equatorial entre 14 e $21 \mu \mathrm{m}$.

Dados ecológicos: a família Acanthaceae possui distribuição pantropical. No Brasil ocorrem cerca de 200 gêneros e 500 espécies, em áreas abertas e florestais (Souza \& Lorenzi, 2008). Durante saídas a campo foi coletada no PESP a espécie Justicia laevilinguis (HERULBRA 4462).

Família Verbenaceae

\section{Verbenaceae}

(Fig. 101)

Descrição: mônade, grão de pólen médio, âmbito subtriangular, suboblato, tricolporado, endoabertura lalongada, exina microrreticulada medindo $2 \mu \mathrm{m}$; nexina mais espessa que a sexina.

Dimensões (6 espécimes): diâmetro polar entre 26 e $33 \mu \mathrm{m}$, diâmetro equatorial entre 27 e $33 \mu \mathrm{m}$.

Dados ecológicos: no PESP ocorrem quatro espécies herbáceas: Glandularia subincana Tronc., Lipia asperrima Cham., Verbena gracilescens (Cham.) Herter e V. montevidensis Spreng., associadas à Savana Estépica Parque e borda da Mata Ciliar (Galvani \& Baptista, 2003).

\section{Família Lamiaceae}

Hyptis Jacq.

(Fig. 102)

Descrição: mônade, grão de pólen médio, âmbito subcircular, prolato esferoidal, hexacolpado (estefanocolpado), colpos longos, exina reticulada heterobrocada; lúmens com, aproximadamente, 1 m de largura, apresentando pequenas variações em relação ao tamanho e forma; sexina levemente mais espessa que a nexina.

Dimensões (3 espécimes): diâmetro polar entre 33 e $37 \mu \mathrm{m}$, diâmetro equatorial entre 29 e $35 \mu \mathrm{m}$.

Dados ecológicos: erva nativa, no PESP ocorre sempre associada à Savana Estépica Parque (Galvani \& Baptista, 2003).

\section{Scutellaria L.}

(Fig. 103)

Descrição: mônade, grão de pólen pequeno, âmbito subtriangular, prolato esferoidal, tricolpado, colpos longos, exina microrreticulada medindo 1,2 $\mu \mathrm{m}$ de espessura; sexina e nexina de mesma espessura.

Dimensões (3 espécimes): diâmetro polar entre 22 e $25 \mu \mathrm{m}$, diâmetro equatorial entre 20 e $23 \mu \mathrm{m}$.

Dados ecológicos: erva nativa, no PESP ocorre sempre associada à Savana Estépica Parque (Galvani \& Baptista, 2003).

\section{Euasterídeas II}

Ordem Apiales

Família Apiaceae

Eryngium L.

(Fig. 104)
Descrição: mônade, grão de pólen de tamanho médio, isopolares, radiossimétricos, prolato, circular, tricolporado com endoabertura lalongada. Colpos longos com ápices arredondados. Exina psilada.

Dimensões (25 espécimes): diâmetro polar entre 35 e $45 \mu \mathrm{m}$, diâmetro equatorial entre 15 e $20 \mu \mathrm{m}$.

Dados ecológicos: no PESP ocorrem três espécies: Eryngium balansae Wolff., E. ebracteatum Lam., E. floribundum Chamess. \& Schltdl., todas citadas como macrófitas aquáticas tolerantes à seca (Galvani \& Baptista, 2003).

Ordem Asterales

Família Asteraceae

\section{Ambrosia L.}

(Fig. 105)

Descrição: mônade, grão de pólen de tamanho médio, esférico, tricolporado, colpos curtos, endoabertura lalongada, exina cavada medindo $5 \mu \mathrm{m}$ de espessura, espículos distribuídos de forma uniforme em toda superfície da exina.

Dimensões (5 espécimes): diâmetro entre 22 e 26 m. Dados ecológicos: ervas anuais ou perenes, invasoras de culturas ou ruderais (Mondin, 2004).

\section{Dasyphyllum cf. spinescens (Less.) Cabrera}

(Fig. 106)

Descrição: mônade, grão de pólen médio, âmbito subtriangular, prolato esferoidais, tricolporado, colpos longos, endoabertura lalongada, exina microequinada não cavada medindo $2,5 \mu \mathrm{m}$; pseudoporos presentes na região do mesocolpo, limitando-se a sexina; sexina de duas a três vezes mais espessa que a nexina.

Dimensões (2 espécimes): diâmetro polar 32 e 35 $\mu \mathrm{m}$, diâmetro equatorial 33 e $37 \mu \mathrm{m}$.

Dados ecológicos: árvore de até 10 metros de altura que habita preferencialmente solos úmidos e rochosos onde a vegetação não é muito densa. Bastante frequente nos capões e submatas (Cabrera \& Klein, 1973).

\section{Pamphalea DC.}

(Fig. 107)

Descrição: mônade, grão de pólen de tamanho pequeno, âmbito subtriangular, prolato esferoidal, tricolporados, colpos grandes, endoabertura lalongada, exina microequinada não cavada; sexina mais espessa que a nexina.

Dimensões (1 espécime): diâmetro polar $33 \mu \mathrm{m}$, diâmetro equatorial $31 \mu \mathrm{m}$.

Dados ecológicos: erva anual ou perene nativa (Mondin \& Baptista, 1996).

\section{Verbesina L.}

(Fig. 108)

Descrição: mônade, grão de pólen médio, âmbito subtriangular, prolato esferoidal, tricolporado, endoabertura lalongada, exina equinada apresentando cava estreita com $1 \mu \mathrm{m}$ de espessura em VP; presença de 15 espinhos em VP medindo $4 \mu \mathrm{m}$ de altura e $2 \mu \mathrm{m}$ de 

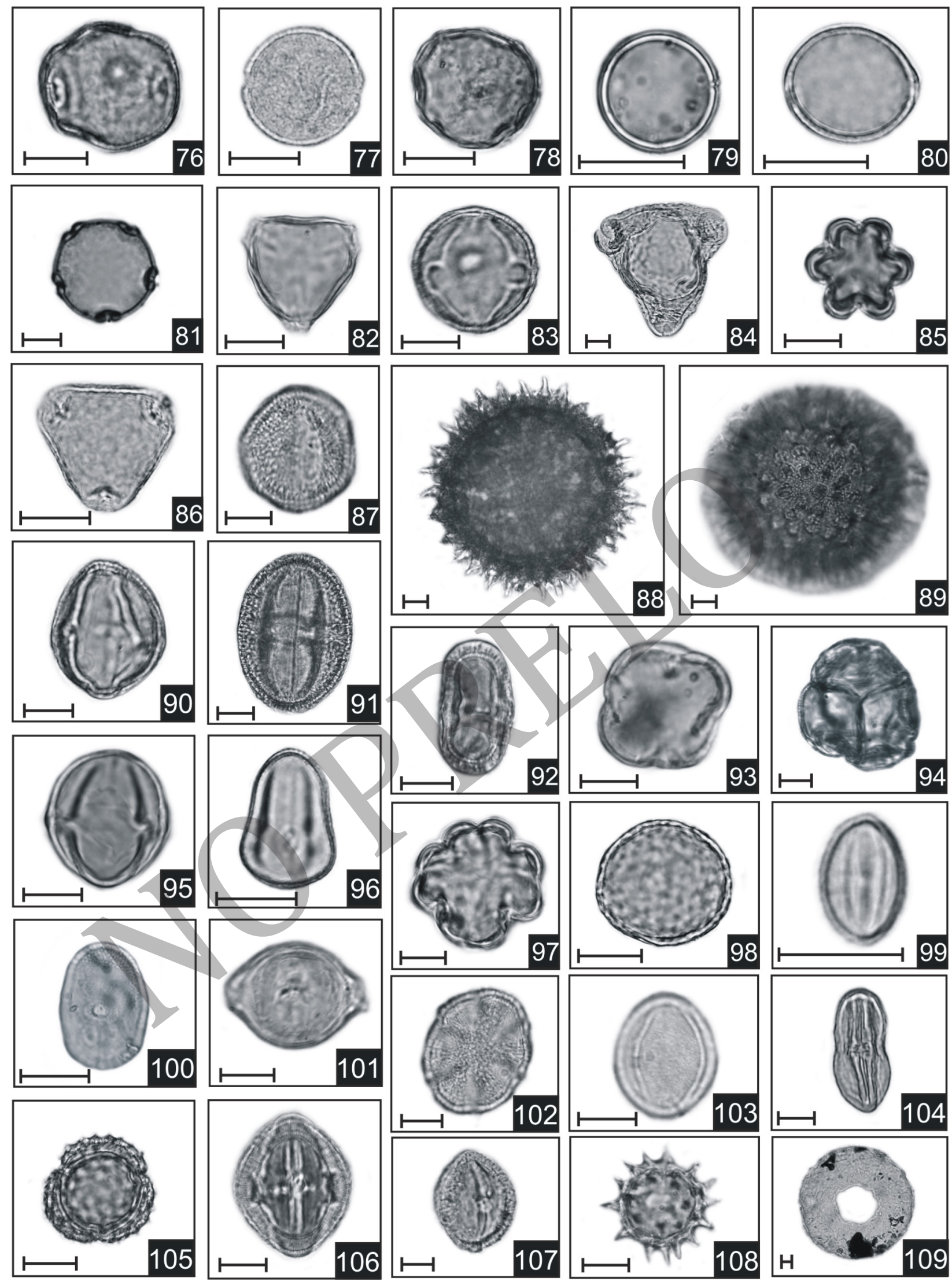

Figuras 76-109. Fotomicrografias de palinomorfos e outros táxons selecionados: 76. Celtis; 77. Trema micrantha; 78. Dorstenia; 79. Moraceae/ Urticaceae; 80. Sorocea bonplandii; 81. Nothofagus; 82. Cuphea; 83. Heymia; 84. Onagraceae; 85. Combretum fruticosum; 86. Myrtaceae; 87. Raphanus; 88-89. Sida cf. rhombifolia; 90. Anacardiaceae; 91. Sapium; 92. Chrysophyllum; 93. Myrsine; 94. Ericaceae; 95. Solanum; 96. Echium plantagineum; 97. Aspidosperma quebracho-blanco; 98. Plantago; 99. Scoparia; 100. Justicia laevilinguis; 101. Verbenaceae; 102. Hyptis; 103. Scutellaria; 104. Eryngium; 105. Ambrosia; 106. Dasyphyllum cf. spinescens; 107. Pamphalea; 108. Verbesina; 109. Tecameba. Escala gráfica correspondente a $10 \mu \mathrm{m}$. 
largura na base.

Dimensões (8 espécimes): diâmetro polar entre 28 e $30 \mu \mathrm{m}$, diâmetro equatorial entre 26 e $30 \mu \mathrm{m}$.

Dados ecológicos: no PESP ocorre a espécie Verbesina subcordata DC., associada à Savana Estépica Parque (Galvani \& Baptista, 2003). São subarbustos eretos que ocorrem em solos secos de campos, capoeiras, ambientes rochosos, ruderal em beira de estrada (Mondin, 2004).

Outros palinomorfos

\section{Tecameba}

(Fig. 109)

Descrição: em vista apical podem ser observados dois círculos concêntricos: o círculo interno representa o pseudostome (tubo bucal) e o círculo externo corresponde à expansão da parte oral.

Dimensões (25 espécimes): diâmetro do círculo maior entre 113 e 135 m e diâmetro do círculo menor entre 40 e $50 \mu \mathrm{m}$.

Dados ecológicos: segundo Bonnet (1974), aproximadamente $80 \%$ das espécies viventes ocupam biótopos aquáticos associados à vegetação marginal e ao sedimento do fundo dos corpos de água.

\section{Considerações finais}

Este artigo apresenta as primeiras descrições morfológicas de palinomorfos ocorrentes na Savana Estépica Parque. Além de atestarem a diversidade polínica local, os resultados permitirão que futuros estudos desenvolvidos nesta formação vegetacional apresentem maior resolução taxonômica.

Adicionalmente aos táxons descritos e ilustrados, foram identificados outros 17 palinomorfos, ausentes nesta publicação uma vez que os poucos espécimes encontrados estavam fragmentados e/ou muito amassados: Apocynaceae, Asteraceae subf. Asteroideae, Balanophoraceae, Bromeliaceae, Cephalanthus, Eclipta cf. bellidioides, Erythrina, Gomphrena, Haloragaceae, Hydrocotyle, Hypochaeris, Iridaceae, Monocotiledônea, Pluchea, Rubiaceae, tipo Baccharis e tipo Senecio.

Agradecimentos- Este trabalho constitui parte da Dissertação de Mestrado da primeira autora, desenvolvida junto ao Programa de Pós-graduação em Geociências da Universidade Federal do Rio Grande do Sul. Os autores agradecem à Fundação 0 Boticário de Proteção à Natureza (Projeto № 0809_20082) e à FAPERGS (Processo № 1012119) pelos subsídios financeiros recebidos e à Secretaria Estadual do Meio Ambiente pela concessão da licença para realização desta pesquisa.

\section{Referências}

Alves, F. da S \& Marchiori, J.N.C. 2011. O inhanduvá no Rio Grande do Sul - Enfoque fitogeográfico. Ciência \& Ambiente, 42: 39-70.

APG III. 2009. An update of the Angiosperm Phylogeny Group classification for the orders and families of flowering plants: APG III. Botanical Journal of the Linnean Society, 161: 105-121.

Backes, A. \& Nardino, M. 2003. Árvores, arbustos e algumas lianas nativas do Rio Grande do Sul. São Leopoldo, Ed. Unisinos, $213 \mathrm{p}$.

Backes, P. \& Irgang, B. 2002. Árvores do Sul. Porto Alegre, Instituto Souza Cruz, 325 p.

Backes, P. \& Irgang, B. 2004. Árvores cultivadas no Sul do Brasil: Guia de identificação e interesse paisagístico das principais espécies exóticas. Porto Alegre, Ed. Paisagem do Sul, $204 \mathrm{p}$.

Barth, O.M. \& Melhem, T.S. 1988. Glossário ilustrado de palinologia. Campinas, Editora da Universidade Estadual de Campinas, 76 p.

Bauermann, S.G. 2003. Análises Palinológicas e Evolução Paleovegetacional e paleoambiental das Turfeiras de Barrocadas e Águas Claras, Planície Costeira do Rio Grande do Sul, Brasil. Porto Alegre. 137p. Tese de Doutorado, Programa de Pós-graduação em Geociências, Instituto de Geociências, Universidade Federal do Rio Grande do Sul.

Bauermann, S.G., Behling, H. \& Macedo, R.B. 2009. Biomas regionais e evolução da paisagem no Rio Grande do Sul com base em paleopalinologia In: Ribeiro, A.M., Bauermann, S.G. \& Scherer, C.S. (Eds.). Quaternário do Rio Grande do Sul e Integrando Conhecimentos. Porto Alegre, Monografias da Sociedade Brasileira de Paleontologia, p. 81-93.

Bauermann, S.G., Evaldt, A.C.P., Zanchin, J.R. \& Bordignon, S.A.L. 2010. Diferenciação polínica de Butia, Euterpe, Geonoma, Syagrus e Thritrinax e implicações paleoecológicas de Arecaceae para o Rio Grande do Sul. Iheringia, Série Botânica, 65: 35-46.

Behling, H. 1993. Untersuchungen zur spätpleistozänen und holozänen Vegetations- und Klimageschichte der tropischen Küstenwälder und der Araukarienwälder in Santa Catarina (Südbrasilien).Berlin, 149 p. Dissertationes Botanicae 206, J. Cramer, Berlin.

Behling, H., Pillar, V.D. \& Bauermann, S.G. 2005. Late Quaternary grassland (Campos), gallery forest, fire and climate dynamics, studied by pollen, charcoal and multivariate analysis of the São Francisco de Assis core in western Rio Grande do Sul (Southern Brazil). Review of Palaeobotany and Palynology, 133: 235-248.

Bonnet, L. 1974. Les Thecamoebiens. In: Puytorac, P. (Eds.) Quelques aspects de la faune des mousses. Annales du Centre Régional de Documentation Pédagogique (C.R.D.P.) de l'Académie de Clermont-Ferrand, 21-30.

Cabrera, L.A. \& Klein, R.M. 1973. Plantas compostas - Tribo: Mutiseae. Flora Ilustrada Catarinense, Compostas: 1-124.

Cancelli, R.R., Evaldt, A.C.P. \& Bauermann, S.G. 2007. Contribuição à morfologia polínica da família Asteraceae Martinov, no Rio Grande do Sul - Parte I. Pesquisas, Série Botânica, 58: 347-374.

Cancelli, R.R., Evaldt, A.C.P., Bauermann, S.G., Souza, P.A., Bodignon, S.A.L. \& Matzenbacher, N.I. 2010. Catálogo palinológico de táxons da família Asteraceae Martinov, no Rio Grande do Sul, Brasil. Iheringia, Série Botânica, 65: 201-280.

Cancelli, R.R., Souza, P.A. \& Neves, P.C.P. 2012a. Fungos, criptógamas e outros palinomorfos holocênicos $(7908 \pm 30$ anos AP - atual) da Planície Costeira sul-catarinense, Brasil. Acta Botanica Brasilica, 26(1): 27-44.

Cancelli, R.R., Souza, P.A. \& Neves, P.C.P. 2012b. Grãos de pólen de angiospermas do Holoceno (7908 \pm 30 anos AP- 
-atual) da Planície Costeira sul-catarinense, Brasil. Acta Botanica Brasilica, 26(4): 866-885.

Colinvaux, P., Oliveira, P.E. \& Patiño, J.E.M. 1999. Amazon Pollen Manual and Atlas. The Netherlands, Harwood Academic Publishers, $332 \mathrm{p}$.

Cronquist, A. 1981. An integrated system of classification of flowering plants. New York, Columbia University Press, $1262 \mathrm{p}$.

Da-Rosa, A.A.S. 2009. Geologia do Quaternário continental do RS: estado da arte e perspectivas de trabalho. In: A.M. Ribeiro, S.G. Bauermann \& C.S. Scherer (Eds) Quaternário do Rio Grande do Sul: integrando conhecimentos, Porto Alegre, Monografias da Sociedade Brasileira de Paleontologia, p. 17-34.

Domsch, K.H., Gams, W. \& Anderson, T.H. 1980. Compendium of soil fungi. London, Academic Press, 630 p.

Evaldt, A.C.P., Bauermann, S.G., Fuchs, S.C.B., Diesel, S. \& Cancelli, R.R. 2009. Grãos de pólen esporos do Vale do Rio Caí, nordeste do Rio Grande do Sul, Brasil: descrições morfológicas e implicações paleoecológicas. Gaea, 5(2): 86-106.

Evaldt, A.C.P., Bauermann, S.G., Cancelli, R.R., Acioli, M. \& Neves, P.C.P. 2011. Morfologia polínica de Passifloraceae Juss. ex Kunth. no Rio Grande do Sul, Brasil. Revista Brasileira de Biociências, 9(1): 75-87.

Evaldt, A.C.P., Bauermann, S.G. \& Souza, P.A. Registros polínicos para o Holoceno tardio da região da Campanha (Rio Grande do Sul, Brasil) e seu significado na história da sucessão vegetacional da Savana Estépica Parque. Revista Brasileira de Paleontologia, submetido.

Faegri, K. \& Iversen, L. 1989. Textbook of pollen analysis. 4a ed. New York, John Wiley. 486p.

Galvani, F.R. \& Baptista, L.R.M. 2003. Flora do Parque Estadual do Espinilho - Barra do Quaraí, RS. Revista da FZVA, 10(1): 42-62.

Guiry, M.D. \& Guiry, G.M. 2012. Algae Base. World-wide electronic publication, National University of Ireland, Galway. Disponível em: http://www.algaebase.org >. Acesso em: 30 jul. 2012.

Hässel de Menéndez, G.G. 1962. Estudio de las Anthocerotales y Marchantiales de la Argentina. Tucumán: Universidad Nacional de Tucumán, Instituto Miguel Lillo, 325 p.

Hässel de Menéndez, G.G.1987. Phaeoceros laevis (L.) Prosk. and P. carolinianus (Michx.) Prosk., their spores. Jornal Hattori Botanical Laboratory, 62: 281-288.

Heusser, C.J. 1971. Pollen and spores of Chile. Tucson, The University of Arizona Press, 167 p.

Hibbett, D.S., Binder, M., Bischoff , J.F., Blackwell, M. Cannon, P.F., Eriksson, O.E., Huhndorf, S., James, T, Kirk, P.M., Lücking, R., Lumbsch, H.T., Lutzoni, F., Matheny, P.B., McLaughlin, D.J., Powel, M.J., Redhead, S., Schoch, C.L., Spatafora, J.W., Stalpers, J.A., Vilgalys, R., Aime, M.C., Aptroot, A., Bauer, R., Begerow, D., Benny, G.L., Castlebury, L.A., Crous, P.W., Dai, Y., Gams, W., Geiser, D.M., Griffith, G.W., Gueidan, C., Hawksworth, D.L., Hestmark, G., Hosaka, K., Humber, R.A., Hyde, K.D., Ironside, J.E., Kõljalg, U., Kurtzman, C.P., Larsson, K., Lichtwardt, R., Longcore, J., Miądlikowska, J., Miller, A., Moncalvo. J., Mozley-Standridge, S., Oberwinkler, F., Parmasto, E., Reeb, V., Rogers, J.D., Roux, C., Ryvarden, L., Sampaio, J.P., Schüßler, A., Sugiyama, J., Thorn, R.G., Tibell, L., Untereiner, W.A., Walker, C., Wang, Z., Weir, A., Weiss, M.,White, M.M. Winka, K., Yao, Y. \& Zhang, N. 2007. A higher-level phylogenetic classification of the Fungi. Science Direct. Mycological Research, 3: 509-
547.

Hooghiemstra, H. 1984. Vegetational and climatic history of the high plain of Bogotá, Colombia: a continuous record of the last 3.5 million years. Vaduz, Strauss \& Cramer, 368 p.

IBGE - Instituto Brasileiro de Geografia e Estatística. 1992. Manual técnico da vegetação brasileira. Rio de Janeiro, IBGE, 153 p.

Kapp, R.O., Davis, O.K. \& King, J.E. 2000. Pollen and Spores. Michigan, American Association of Stratigraphic Palynologists, $279 \mathrm{p}$.

Leonhardt, A. \& Lorscheitter, M.L. 2007. Palinomorfos do perfil sedimentar de uma turfeira em São Francisco de Paula, Planalto Leste do Rio Grande do Sul, Sul do Brasil. Revista Brasileira de Botânica, 30(1): 45-57.

Lista de espécies da Flora do Brasil. 2012. Disponível em:<http://floradobrasil.jbrj.gov.br/2012> Acesso em 15 de mai. 2012.

Lorenzi, H. 2003. Árvores Exóticas no Brasil - Madeireiras, ornamentais e aromáticas. Nova Odessa, Instituto Plantarum, $368 \mathrm{p}$.

Lorscheitter, M.L. 1988. Palinologia de sedimentos quaternários do testemunho T15, Cone do Rio Grande, Atlântico Sul, Brasil. Descrições taxonômicas. Pesquisas, Série Botânica, 21: 61-117.

Lorscheitter, M.L., Ashraf, A.R., Bueno, R.M. \& Mosbrugger, V. 1998. Pteridophyte spores of Rio Grande do Sul flora, Brazil. Part I. Palaeontographica, Abt. B. 246: 1-113.

Lorscheitter, M.L., Ashraf, A.R., Bueno, R.M. \& Mosbrugger, V. 1999. Pteridophyte spores of Rio Grande do Sul flora, Brazil. Part II. Palaeontographica, Abt. B. 251: 71-235.

Lorscheitter, M.L., Ashraf, A.R., Bueno, R.M. \& Mosbrugger, V. 2001. Pteridophyte spores of Rio Grande do Sul flora, Brazil. Part III. Palaeontographica, Abt. B. 260: 1-165.

Lorscheitter, M.L., Ashraf, A.R., Bueno, R.M. \& Mosbrugger, V. 2002. Pteridophyte spores of Rio Grande do Sul flora, Brazil. Part IV. Palaeontographica, Abteilung B: Paläophytologie 263: 1-159.

Lorscheitter, M.L., Ashraf, A.R., Bueno, R.M. \& Mosbrugger, V. 2005. Pteridophyte spores of Rio Grande do Sul flora, Brazil. Part V. Palaeontographica, Abteilung B: Paläophytologie 270: 1-180.

Macedo, R.B., Souza, P.A. \& Bauermann, S.G. 2009. Catálogo de pólens, esporos e demais palinomorfos em sedimentos holocênicos de Santo Antônio da Patrulha, Rio Grande do Sul, Brasil. Iheringia, Série Botânica, 64 (2): 43-78.

Marchioretto, M.S., Windisch, P.G. \& Siqueira, J.C. 2004. Padrões de distribuição geográfica das espécies de Froelichia Moench e Froelichiella R.E. Fries (Amaranthaceae) no Brasil. Iheringia, Série Botânica, 59 (2): 149-159.

Markgraf, V. \& D’Antoni, H. 1978. Pollen flora of Argentina. Tucson, University of Arizona Press, 208 p.

Medeanic, S. 2006. Freshwater algal palynomorph records from Holocene depositsin the Coastal Plain of the Rio Grande do Sul, Brazil. Review of Paleobotany and Palynology, 141: 83-101.

Melhem, T.S., Cruz-Barros, M.A.V., Corrêa, A.M.S., Makino-Watanabe, H., Silvestre-Capelato, M.S.F. \& Gonçalves-Esteves, V.L. 2003. Variabilidade polínica em plantas de Campos do Jordão (São Paulo, Brasil). Boletim do Instituto de Botânica, 16: 1-104.

Mondin, C.A. 2004. Levantamento da tribo Heliantheae Cass. (Asteraceae), sensu stricto, no Rio Grande do Sul, Brasil. Porto Alegre. 344p. Tese de Doutorado, Programa de Pós-graduação em Botânica, Instituto de Biociências, Univer- 
sidade Federal do Rio Grande do Sul.

Mondin, C. A. \& Baptista, L. R. M. 1996. Relações biogeográficas da tribo Mutisieae Cass. (Asteraceae), sensu Cabrera, no Rio Grande do Sul. Comunicações do Museu de Ciências Tecnologia (PUC/RS), 2(1): 49-152.

Mondin, C.A., Cervi, A.C. \& Moreira, G.R. 2011. Sinopse das espécies de Passiflora L. (Passifloraceae) do Rio Grande do Sul, Brasil. Revista Brasileira de Biociências, 9(1): 3-27.

Neves, P.C.P. 1998. Palinologia de sedimentos quaternários no Estado do Rio Grande do Sul, Brasil: Guaíba e Capão do Leão. Porto Alegre. 513p. Tese de Doutorado, Programa de Pós-graduação em Geociências, Instituto de Geociências, Universidade Federal do Rio Grande do Sul.

Neves, P.C.P. \& Lorscheitter, M.L. 1992. Palinologia de sedimentos de uma mata tropical paludosa em Terra de Areia, Planície Costeira Norte, Rio Grande do Sul, Brasil. Descrições Taxonômicas, Parte I: fungos, algas, briófitos, pteridófitos, palinomorfos outros e fragmentos de invertebrados. Acta Geologica Leopoldensia, 15(36): 83-114.

Neves, P.C.P. \& Bauermann, S.G. 2003. Catálogo Palinológico de Coberturas Quaternárias do Estado do Rio Grande do Sul (Guaíba e Capão do Leão), Brasil. Descrições Taxonômicas - Parte I: Fungos, Algas, palinomorfos outros e fragmentos de invertebrados. Pesquisas, Série Botânica, 53: 121-149.

Neves, P.C.P. \& Bauermann, S.G. 2004. Catálogo Palinológico de Coberturas Quaternárias no Estado do Rio Grande do Sul (Guaíba e Capão do Leão), Brasil. Descrições Taxonômicas - Parte II: Bryophyta e Pteridophyta. Pesquisas, Série Botânica, 55: 227-251.

Pire, S.M., Anzótegui, L.M. \& Cuadrado, G.A. 2006. Flora Polínica del Nordeste Argentino. Corrientes, Ed. Eudene, 172 p.

Punt, W., Hoen, P.P., Blackmore, S., Nilsson, S. \& Le Thomas, A. 2007. Glossary of pollen and spore terminology. Review of Paleobotany and Palynology, 143: 1-81.

Radaeski, J.N., Evaldt, A.C.P., Lima, G.L. \& Bauermann, S.G. 2011. Grãos de pólen das formações campestres sul-brasileiras. Revista de Iniciação Científica da ULBRA, 9: 59-67.

Reif, C. \& Andreata, R.H.P. 2011. Contribuição à taxonomia de Loranthaceae no Estado do Rio de Janeiro, Brasil. Pesquisas, Série Botânica, 62: 71-115.

Rich, F.J. \& Pirkle, F.L. Paleoecological interpretation of the Trail Ridge sequence, and related deposits in Georgia and Florida, based on pollen sedimentation and clastic sedimentology. In: Traverse, A. (ed.). 1994. Sedimentation of Organic Particles. Cambridge, University Press, 543 p.

Rio Grande do Sul. 2012. Atlas Climático Rio Grande do Sul. Disponível em: < http://www.r3pb.com.br/ AtlasCemetRS/\#/I/zoomed.>. Acesso em: 8 out. 2012.

Rossignol, M. 1962. Analyse polinique de sediments marins quaternaires en Israel. II Sédments pleistocenes. Pollen et Spores, 4(1): 121-148.

Roth, L. \& Lorscheitter, M.L. 2008. Palinomorfos de um perfil sedimentar em uma turfeira do Parque Nacional dos Aparados da Serra, leste do Planalto do Rio Grande do Sul, Brasil. Iheringia, 63(1): 69-100.

Roubik, D.W. \& Moreno, J.E. 1991. Pollen and Spores of Barro Colorado Island. St. Louis, Missouri Botanical Garden, 268 p.

Salgado-Labouriau, M.L. 2007. Critérios e técnicas para o Quaternário. São Paulo, Ed. Blücher, 387 p.

Scherer, C. \& Lorscheitter, M.L. 2008. Palinomorfos de fungos e criptógamas em sedimentos quaternários de duas matas com Araucária, Planalto leste do Rio Grande do Sul, Brasil. Acta Botanica Brasilica, 22: 131-144.

Sobral, M., Jarenkov, J.A., Brack, P., Irgang, B., Larocca, J. \& Rodrigues, R.S. 2006. Flora arbórea e arborescente do Rio Grande do Sul, Brasil. Porto Alegre, Ed. Novo Ambiente, $350 \mathrm{p}$.

Souza, V.C. \& Lorenzi, H. 2008. Botânica sistemática: guia ilustrado para identificação das famílias de fanerógamas nativas e exóticas no Brasil, baseado em APG II. São Paulo, Instituto Plantarum, 704 p.

The International Plant Name Index. 2005. Disponível em <http://www.ipni.org> Acesso em 15 de mai. 2012.

Torgan, L.C., Barreda, K.A. \& Fortes, D.E. 2001. Catálogo das algas Chlorophyta de águas continentais e marinhas do estado do Rio Grande do Sul, Brasil. Iheringia, 56: 147183.

Trufem, S.F.B. 1999. Taxonomia de zigomicetos. In: Bononi, V.L.R. (Ed) Zigomicetos, Basidiomicetos e Deuteromicetos: noções básicas de taxonomia e aplicações biotecnológicas. São Paulo, Instituto de Botânica, Secretaria do Meio Ambiente, p. 19-49.

Tryon, R.M. \& Tryon, A.F. 1982. Ferns and allied plants with special reference to tropical America. New York, Springer Verlag, $857 \mathrm{p}$.

van Geel, B. 1978. A palaeoecological study of Holocene peat bog sections in Germany and the Netherland, based on the analysis of pollen, spores and macro and microscopic remains of fungi, algae, cormophytes and animals. Review of Palaeobotany and Palynology, 25: 1-120.

van Geel, B. \& van der Hammen, T. Zignemataceaein quaternary colombian sediments. Review of Palaeobotany and Palynology, 25: 377-392.

von Arx, J.A. 1974. The genera of Fungi Sporulating in Pure Culture. Valuz, Ed. Cramer.

Watzlawick, L.F., Longhi, S.J., Schneider, P.R., Finger, C.A.G \& Longhi, R.V. 2010. Caracterização e dinâmica da vegetação de uma savana estépica parque, Barra do Quaraí, RS. Pesquisa Florestal Brasileira, 30(64): 363-368.
Manuscrito 511.

Editores: César L. Schultz e Maria do Carmo Lima e Cunha 
Apêndice 1. Lista dos táxons identificados nos sedimentos holocênicos e superficiais da Savana Estépica Parque, Barra do Quaraí (RS), com respectivas fontes das ilustrações (código das lâminas: Palinoteca da ULBRA) e indicação de figura neste trabalho. AS: amostras superficiais; AT: amostras do testemunho.

\begin{tabular}{|c|c|c|c|c|c|}
\hline \multirow[t]{2}{*}{ Palinomorfos } & \multicolumn{2}{|c|}{ Ocorrências } & \multirow[t]{2}{*}{ Lâmina } & \multirow{2}{*}{$\begin{array}{c}\text { Coordenada } \\
\text { England Finder }\end{array}$} & \multirow[t]{2}{*}{ Ilustração } \\
\hline & AS & AT & & & \\
\hline Glomus & $\mathrm{X}$ & $\mathrm{X}$ & P-1206b, P-1114a & C393-e, C244-f & Fig. 2-3 \\
\hline Tetraplosphaeria tetraploa & $\mathrm{X}$ & & P-1205d & B335-c & Fig. 4 \\
\hline Bryophytomyces sphagni & $\mathrm{X}$ & $\mathrm{X}$ & P-1138a & B147-e & Fig. 5 \\
\hline Ascósporo tipo Chaetomium & $\mathrm{X}$ & $\mathrm{X}$ & P- $1211 c$ & B608-h & Fig. 6 \\
\hline Gelasinospora adjuncta & & $\mathrm{X}$ & P-1133a & B312-c & Fig. 7 \\
\hline Khuskia & $\mathrm{X}$ & $\mathrm{X}$ & P-1205a & B734-e & Fig. 8 \\
\hline Gaeumannomyces cf. caricis & $\mathrm{X}$ & $\mathrm{X}$ & $\mathrm{P}-1211 \mathrm{c}$ & B199-f & Fig. 9 \\
\hline Esporo indeterminado 1 & $\mathrm{X}$ & $\mathrm{X}$ & P-1123d & C124-e & Fig. 10 \\
\hline Esporo indeterminado 2 & $\mathrm{X}$ & $\mathrm{X}$ & $P-1145 c$ & B38-g & Fig. 11 \\
\hline Esporo indeterminado 3 & $\mathrm{X}$ & $\mathrm{X}$ & P-1123d & B297-a & Fig. 12 \\
\hline Esporo indeterminado 4 & $\mathrm{X}$ & $\mathrm{X}$ & P-1133b & B851-b & Fig. 13 \\
\hline Esporo indeterminado 5 & $\mathrm{X}$ & $\mathrm{X}$ & P-1185d & B624-c & Fig. 14 \\
\hline Esporo indeterminado 6 & $\mathrm{X}$ & $\mathrm{X}$ & P-1114a & C167-f & Fig. 15 \\
\hline Esporo indeterminado 7 & $\mathrm{X}$ & $\mathrm{X}$ & $\mathrm{P}-1158 \mathrm{c}$ & B158-a & Fig. 16 \\
\hline Esporo indeterminado 8 & $\mathrm{X}$ & $\mathrm{X}$ & $P-1159 c$ & B281-g & Fig. 17 \\
\hline Esporo indeterminado 9 & $\mathrm{X}$ & $\mathrm{X}$ & P-1158c & B403-f & Fig. 18 \\
\hline Frutificação de fungo & $\mathrm{X}$ & $\mathrm{X}$ & P-1209c & B643-f & Fig. 19 \\
\hline Hifa de fungo & $\mathrm{X}$ & $\mathrm{X}$ & P-1205d & B664i & Fig. 20 \\
\hline Botryococcus & $\mathrm{X}$ & $\mathrm{X}$ & P-1211c & B541-d & Fig. 21 \\
\hline Debarya & $\mathrm{X}$ & $x$ & P-1145b & B407-e & Fig. 22 \\
\hline Spirogyra & $\mathrm{X}$ & $\mathrm{X}$ & P-1217c & B72-h & Fig. 23 \\
\hline Pseudoschizaea rubina & $\mathrm{X}$ & $\mathrm{X}$ & P-1158c & B802-g & Fig. 24 \\
\hline Bartramia & $x$ & & P-1123d & B267-g & Fig. 25 \\
\hline Phaeoceros laevis & & & $\mathrm{P}-1211 \mathrm{~b}$ & B270-e & Fig. 26 \\
\hline tipo Microgramma vacciniifolia & $\mathrm{X}$ & $\mathrm{X}$ & P-1217a & B346-f & Fig. 27 \\
\hline Cyatheaceae & $X$ & & P-1207a & A690-d & Fig. 28 \\
\hline tipo Blechnum & $\mathrm{X}$ & & P-1207a & B433-d & Fig. 29 \\
\hline Adianthaceae & $x$ & & P-1207b & B197-b & Fig. 30 \\
\hline Esporo trilete indeterminado & $\mathrm{X}$ & & $\mathrm{P}-1214 \mathrm{a}$ & B40-b & Fig. 31 \\
\hline Esporo trilete indeterminado 2 & $\mathrm{X}$ & & P-1214a & B105-c & Fig. 32 \\
\hline Pinus & $\mathrm{X}$ & & P-1216d & B867-c & Fig. 33 \\
\hline Nectandra & $\mathrm{X}$ & & P-1207a & B132-i & Fig. 34 \\
\hline Peperomia & $\mathrm{X}$ & & P-1290a & B291-b & Fig. 35 \\
\hline Lemna & $\mathrm{X}$ & $\mathrm{X}$ & P-1200b & B597-c & Fig. 36 \\
\hline Echinodorus grandiflorus & $\mathrm{X}$ & $\mathrm{X}$ & P-1214a & C751-d & Fig. 37 \\
\hline Sagittaria montevidensis & $\mathrm{X}$ & $\mathrm{X}$ & $P-1213 b$ & B425-g & Fig. 38 \\
\hline Potamogeton & $\mathrm{X}$ & & P-1200a & B197-d & Fig. 39 \\
\hline Sisyrinchium & $\mathrm{X}$ & $\mathrm{X}$ & P-1213a & B307-b & Fig. 40 \\
\hline tipo Butia & $\mathrm{X}$ & $\mathrm{X}$ & P-1217b & B61-a & Fig. 41 \\
\hline Tradescantia & $\mathrm{X}$ & & P-1290b & B72-a & Fig. 42 \\
\hline Pontederia & $\mathrm{X}$ & $\mathrm{X}$ & $\mathrm{P}-1137 \mathrm{c}$ & B510-d & Fig. 43 \\
\hline Tillandsia & $\mathrm{X}$ & $\mathrm{X}$ & $\mathrm{P}-1214 \mathrm{a}$ & B222-h & Fig. 44 \\
\hline Eriocaulaceae & $\mathrm{X}$ & $\mathrm{X}$ & $P-1205 a$ & C32-g & Fig. 45 \\
\hline Juncaceae & $\mathrm{X}$ & $\mathrm{X}$ & P-1208 & B771-e & Fig. 46 \\
\hline Cyperaceae & $\mathrm{X}$ & $\mathrm{X}$ & P-1206b & B242-d & Fig. 47 \\
\hline Poaceae & $\mathrm{X}$ & $\mathrm{X}$ & P-1217a & C34-g & Fig. 48 \\
\hline tipo Amaranthus L./Chenopodiaceae & $\mathrm{X}$ & & $\mathrm{P}-1211 \mathrm{a}$ & B565-b & Fig. 49 \\
\hline Froelichia tomentosa & $\mathrm{X}$ & & P-1204a & B299-c & Fig. 50 \\
\hline Pfaffia & $\mathrm{X}$ & $\mathrm{X}$ & P-1290a & B500-a & Fig. 51 \\
\hline Opuntia & $\mathrm{X}$ & & P-1216b & B333-e & Fig. 52 \\
\hline Polygolum cf. hydropiperoides & $\mathrm{X}$ & & P-1207b & B623-i & Fig. 53 \\
\hline Struthanthus & $\mathrm{X}$ & $\mathrm{X}$ & P-1205a & B372-e & Fig. 54 \\
\hline Myriophyllum & $\mathrm{X}$ & $\mathrm{X}$ & $\mathrm{P}-1211 \mathrm{c}$ & B304-i & Fig. 55 \\
\hline Oxalis & $\mathrm{X}$ & $\mathrm{X}$ & $P-1209 a$ & C331-c & Fig. 56 \\
\hline Maytenus & $\mathrm{X}$ & & $P-1210 c$ & B320-b & Fig. 57 \\
\hline
\end{tabular}


Evaldt et al.

Apêndice 1. Continuação.

\begin{tabular}{|c|c|c|c|c|c|}
\hline Janusia guaranitica & $\mathrm{X}$ & $\mathrm{X}$ & P-1216a & A60-c & Fig. 58 \\
\hline Malpighiaceae & $\mathrm{X}$ & $\mathrm{X}$ & P-1211a & A119-e & Fig. 59 \\
\hline Acalypha & $\mathrm{X}$ & & P-1211a & B118-f & Fig. 60 \\
\hline Euphorbiaceae & $\mathrm{X}$ & $\mathrm{X}$ & P-1139b & B402-h & Fig. 61 \\
\hline Sebastiania & $\mathrm{X}$ & $\mathrm{X}$ & P-1200b & B297-e & Fig. 62 \\
\hline Passiflora (sp. 1) & $\mathrm{X}$ & & P-1214b & B217-f & Fig. 63 \\
\hline Passiflora (sp. 2) & $\mathrm{X}$ & & $\mathrm{P}-1211 \mathrm{~b}$ & B183-c & Fig. 64 \\
\hline Salix humboldtiana & $\mathrm{X}$ & $\mathrm{X}$ & P-1208a & B205-c & Fig. 65 \\
\hline Caesalpinia & $\mathrm{X}$ & & P-1208d & B327-a & Fig. 66 \\
\hline Erythrina & $\mathrm{X}$ & & P-1216d & B487-e & Fig. 67 \\
\hline Fabaceae & $\mathrm{X}$ & $\mathrm{X}$ & P-1214b & B333-c & Fig. 68 \\
\hline Mimosoideae & $X$ & $\mathrm{X}$ & P-1212c & A210-c & Fig. 69 \\
\hline Parkinsonia aculeata & $\mathrm{X}$ & $\mathrm{X}$ & P-1290a & B536-g & Fig. 70 \\
\hline Prosopis & $\mathrm{X}$ & $\mathrm{X}$ & $\mathrm{P}-1217 \mathrm{a}$ & B259-h & Fig. 71 \\
\hline Vachellia caven & $\mathrm{X}$ & $\mathrm{X}$ & P-1137b & B415-a & Fig. $72-73$ \\
\hline Polygalaceae & $\mathrm{X}$ & $\mathrm{X}$ & P-1137b & B477-c & Fig. 74 \\
\hline Rosaceae & $X$ & $\mathrm{X}$ & P-1205d & B361-d & Fig. 75 \\
\hline Celtis & $\mathrm{X}$ & $\mathrm{X}$ & P-1217b & B77-i & Fig. 76 \\
\hline Trema micrantha & $\mathrm{X}$ & $\mathrm{X}$ & P-1210a & B457-b & Fig. 77 \\
\hline Dorstenia & $\mathrm{X}$ & $\mathrm{X}$ & P-1135a & B291-c & Fig. 78 \\
\hline Moraceae/ Urticaceae & $\mathrm{X}$ & $\mathrm{X}$ & P-1137b & B415-e & Fig. 79 \\
\hline Sorocea bonplandii & $X$ & & P-1170c & B592-e & Fig. 80 \\
\hline Nothofagus & $\mathrm{X}$ & & P1207a & B-397-c & Fig. 81 \\
\hline Cuphea & $\mathrm{X}$ & 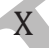 & P-1135a & B291-c & Fig. 82 \\
\hline Heymia & $\mathrm{X}$ & $\mathrm{X}$ & P-1137c & B700-d & Fig. 83 \\
\hline Onagraceae & $\mathrm{X}$ & & $\mathrm{P}-1214 \mathrm{~b}$ & B270-b & Fig. 84 \\
\hline Combretum fruticosum & $\mathrm{X}$ & $\mathrm{X}$ & P-1170c & B592-d & Fig. 85 \\
\hline Myrtaceae & $\mathrm{X}$ & & P-1139a & B286-b & Fig. 86 \\
\hline Raphanus & $\mathrm{X}$ & $\mathrm{X}$ & P-1216d & B457-e & Fig. 87 \\
\hline Sida cf. rhombifolia & $\mathrm{X}$ & $\mathrm{X}$ & P-1206a & B124-e & Fig. 88-89 \\
\hline Anacardiaceae & $\mathrm{X}$ & $\mathrm{X}$ & P-1211a & B61-h & Fig. 90 \\
\hline Sapium & $X$ & $\mathrm{X}$ & $\mathrm{P}-1211 \mathrm{a}$ & B192-a & Fig. 91 \\
\hline Chrysophyllum & $\mathrm{X}$ & & P-1217b & B243-i & Fig. 92 \\
\hline Myrsine & $\mathrm{X}$ & & P-1207a & B115-c & Fig. 93 \\
\hline Ericaceae & $\mathrm{X}$ & & P-1205a & C153-c & Fig. 94 \\
\hline Solanum & $\mathrm{X}$ & $\mathrm{X}$ & $P-1214 b$ & B72-h & Fig. 95 \\
\hline Echium plantagineum & $\mathrm{X}$ & & $P-1125 b$ & B561-h & Fig. 96 \\
\hline Aspidosperma quebracho-blanco & $\mathrm{X}$ & $\mathrm{X}$ & P-1211c & B192-a & Fig. 97 \\
\hline Plantago & $\mathrm{X}$ & $\mathrm{X}$ & P-1214b & B72-h & Fig. 98 \\
\hline Scoparia & $X$ & & P-1211a & B98-e & Fig. 99 \\
\hline Justicia laevilinguis & $\mathrm{X}$ & $\mathrm{X}$ & $\mathrm{P}-1211 \mathrm{a}$ & B309-f & Fig. 100 \\
\hline Verbenaceae & $\mathrm{X}$ & $\mathrm{X}$ & P-1210c & B-35-g & Fig. 101 \\
\hline Hyptis & $\mathrm{X}$ & $\mathrm{X}$ & P-1217 & B560-c & Fig. 102 \\
\hline Scutellaria & $\mathrm{X}$ & $\mathrm{X}$ & $\mathrm{P}-1211 \mathrm{a}$ & B98-e & Fig. 103 \\
\hline Eryngium & $\mathrm{X}$ & $\mathrm{X}$ & P-1211c & B463-c & Fig. 104 \\
\hline Ambrosia & $\mathrm{X}$ & & P-1211c & B204-i & Fig. 105 \\
\hline Dasyphyllum cf. spinescens & $\mathrm{X}$ & $\mathrm{X}$ & $P-1217 b$ & B210-i & Fig. 106 \\
\hline Panphalea & $\mathrm{X}$ & $\mathrm{X}$ & P-1216b & B114-a & Fig. 107 \\
\hline Verbesina & $\mathrm{X}$ & & P-1217b & B196-g & Fig. 108 \\
\hline Tecameba & $\mathrm{X}$ & $\mathrm{X}$ & $\mathrm{P}-1114 \mathrm{c}$ & B64-i & Fig. 109 \\
\hline
\end{tabular}

